Federal Reserve Bank of Minneapolis

Research Department Staff Report 456

Revised June 2013

\title{
Structural Change in an Open Economy*
}

\author{
Timothy Uy \\ University of Minnesota
}

Kei-Mu Yi

Federal Reserve Bank of Minneapolis

Jing Zhang

Federal Reserve Bank of Chicago

\begin{abstract}
We study the importance of international trade in structural change. Our framework has both productivity and trade cost shocks, and allows for non-unitary income and substitution elasticities. We calibrate our model to investigate South Korea's structural change between 1971 and 2005. We find that the shock processes, propagated through the model's two main transmission mechanisms, non-homothetic preferences and the open economy, explain virtually all of the evolution of agriculture and services labor shares, and the rising part of the hump-shape in manufacturing. Counterfactual exercises show that the role of the open economy is quantitatively important for explaining South Korea's structural change.
\end{abstract}

JEL: F20, F40, O13, O41

Keywords: structural transformation, international trade, sectoral labor reallocation

*Uy: uyxx0005@umn.edu, Yi: Kei-Mu.Yi@mpls.frb.org, Zhang: Jing.Zhang@chi.frb.org. We thank our editor, the referee, George Alessandria, Roc Armenter, Satyajit Chatterjee, Margarida Duarte, Daniel Green, Veronica Guerrieri, Ayhan Kose, Dirk Krueger, Andrei Levchenko, Diego Restuccia, Kim Ruhl, Mark Spiegel, Nancy Stokey, Linda Tesar, Michael Waugh, and participants at the Midwest Macro conference, SED conference, Philadelphia Fed, U. of Toronto RMM conference, Michigan State, Michigan, Columbia, Harvard, Missouri, SUNY-Albany, Princeton, HKUST, Minneapolis Fed, Boston Fed, the Canon Institute of Global Studies conference, Dartmouth, New York Fed, NYU, Syracuse, and the Tsinghua University Conference. Mohan Anand, Daniel Green, Jingyi Jiang, Behzad Kianian, and Nandita Mittal provided excellent research assistance. The views expressed herein are those of the author and not necessarily those of the Federal Reserve Bank of Minneapolis or the Federal Reserve System. 


\section{Introduction}

Two of the most important developments affecting the world's economies in the past halfcentury have been global integration, particularly in international trade, and the emergence of a hump-shaped pattern in manufacturing employment shares for many middle and upperincome countries. Employment shares in manufacturing were previously thought to be increasing monotonically as countries develop. However, recent research by Maddison (1991) and Buera and Kaboski (2012), among others, shows for many countries that structural change involves three distinct patterns: a decline in agriculture, a rise in services, and a hump-shaped pattern in manufacturing labor shares.

Global integration between developed and emerging market economies is often blamed for the decline in manufacturing in most developed countries. Indeed, Autor, Dorn, and Hanson (2011) find that one-third of the decline in U.S. manufacturing employment is a result of trade with China. Moreover, some of the emerging market economies that recently joined the global trading system, such as South Korea and Taiwan, have themselves experienced a hump-shaped pattern in manufacturing employment. These findings plausibly suggest a linkage between globalization and structural change. Theoretically, such a linkage is natural: after all, the fundamental role of international trade is to facilitate specialization via an efficient reallocation of employment and other factors of production across sectors.

The main goals of our paper are to develop a multi-sector open economy model to study these linkages, and to conduct a quantitative analysis of the role of international trade in South Korea's structural change. Our model draws from three intellectual antecedents. First, there is the long literature, going back to Engel, that emphasizes the importance of non-unitary sectoral income elasticities - in particular an agriculture/food income elasticity of demand less than one. We embody this with the Stone-Geary non-homothetic preferences. Second, there is the literature, going back to Baumol (1967), that emphasizes the importance of non-unitary sectoral substitution elasticities in conjunction with asymmetric productivity growth across sectors. We allow for these forces in our model, as well. Finally, we introduce 
international trade via the Ricardian comparative advantage framework of Eaton and Kortum (2002). Patterns of specialization and international trade are determined by relative productivity differences across countries and goods. One additional feature of our model, incorporating intermediate goods, is useful for matching gross output concepts like trade and consumption expenditure, with value-added concepts like GDP and labor shares. Overall, our model shares features similar to other multi-sector Eaton-Kortum models such as Shikher (2012), di Giovanni, Levchenko and Zhang (2012), Levchenko and Zhang (2012), and Caliendo and Parro (2011) $!^{1}$

At the most basic level, international trade allows sectoral expenditure to deviate from sectoral production. Each country runs a net export surplus in its sector of comparative advantage. Hence, labor shares are directly affected by patterns of specialization induced by trade. In addition, trade affects relative prices, which affects sectoral expenditure shares, and hence sectoral labor shares.

In a simplified version of the model, we show how productivity shocks and trade cost shocks can qualitatively deliver the structural change patterns observed in South Korea. In particular, the hump-shape in manufacturing can be generated under one of two scenarios. First, if a country's productivity growth in manufacturing is sufficiently high, it will take market share from the other country, thus leading to increased labor devoted to manufacturing. This is the upward part of the hump. However, as manufacturing productivity continues to grow, the country will eventually be able to supply the world market with less labor. This leads to the downward part of the hump. Second, if a country has a comparative advantage in manufacturing and trade costs decline so that the comparative advantage is increasingly revealed, a similar result is obtained.

More broadly, international trade affects structural change along three dimensions. First, declines in trade costs affect patterns of specialization, which then affect labor allocations

\footnotetext{
${ }^{1}$ Caliendo and Parro (2011) and Shikher (2012) study the effects of NAFTA on trade and welfare in the NAFTA countries. di Giovanni, Levchenko and Zhang (2012) examine the impact of different Chinese sectoral growth patterns on global welfare. Levchenko and Zhang (2012) study the welfare implications of the evolution of sectoral comparative advantages across countries over time.
} 
across sectors. Second, differential sectoral productivity growth also affects labor allocations, again operating through specialization patterns. Third, lower trade costs spur income growth and strengthen the role of non-homothetic preferences in structural change.

We calibrate our model to South Korea and the rest of the world in 1971 to 2005, focusing on explaining South Korea's structural change. We then simulate the effects of productivity shocks and trade cost shocks in our benchmark model. We find that it can explain virtually all of the evolution of Korea's agriculture and services sector labor shares. It can also explain the rise in Korea's manufacturing labor share. However, it cannot explain the decline in Korea's manufacturing labor share that occurred beginning around 1990. By contrast, a simulation under a closed economy cannot explain the time path of any sectoral labor share. The root mean square error between the implied and observed labor shares is 0.05 in the open economy model and 0.08 in the closed economy model; the closed economy fit is about 60 percent worse.

The open economy model does better because the asymmetric evolution of sectoral productivity gives Korea's manufacturing sector a comparative advantage over time, thus leading to greater labor in manufacturing, and less in agriculture. In addition, Korea's trade costs decline more rapidly in manufacturing than in agriculture, and this leads again to greater specialization in manufacturing and less in agriculture than otherwise. Finally, in the open economy setting, owing to specialization, Korea grows faster, which strengthens the impact of non-homothetic preferences on the labor share dynamics.

We then conduct a series of counterfactual simulations to assess the quantitative importance of trade cost shocks, TFP shocks, and non-homothetic preferences. We find that agriculture and manufacturing are significantly influenced by both changing trade costs and TFP, while the services sector is influenced primarily by TFP changes over time. In addition, we conduct simulations with homothetic preferences. Comparisons between open and closed economy results with both sets of preferences show that non-homothetic preferences matter for the evolution of agriculture and services, but not for manufacturing. 
There is a large literature on structural change. One recent development is to shift the focus from two-sector closed economy frameworks to three-sector frameworks and open economy frameworks ${ }^{2}$ Recent studies of three-sector closed economy models include Echevarria (1997), Kongsamut, Rebelo, and Xie (2001), Ngai and Pissarides (2007), Rogerson (2008), Restuccia, Yang, and Zhu (2008), Foellmi and Zweimuller (2008), Buera and Kaboski (2009, 2012), Duarte and Restuccia (2010), Verma (2012), and Herrendorf, Rogerson and Valentinyi (2012) $]^{3}$ Earlier studies of open economy models of structural change include Matsuyama (1992, 2009) and Echevarria (1995). Echevarria (1995) studies the effect of trade on output composition and overall growth of OECD economies in a small open economy model. Matsuyama (2009) employs a simple Ricardian model to show that high manufacturing productivity growth need not lead to a decline in manufacturing employment.

The two papers most closely related to ours are Betts, Giri, and Verma (hereafter, BGV; 2011) and Sposi (2012). Both study Korea's structural change from a three-sector model. In the former, while several details of the model and calibration are different, BGV also finds that openness matters a great deal $\left.\right|^{4}$ The latter employs a Ricardian model, and also finds that comparative advantage is important. However, owing to a time period that ends in 1995, the paper cannot assess the ability of the model to replicate the hump-shaped pattern in manufacturing $5^{5}$ A third paper, Teignier-Bacque (2012), also studies structural change in Korea (and two other countries), but focuses on the role of the agriculture sector in a two-sector small open economy model $[6$

\footnotetext{
${ }^{2}$ In terms of two-sector frameworks, the sectoral divisions have often been agriculture and non-agriculture, or capital-intensive and labor-intensive. For recent examples of these divisions, see Caselli and Coleman (2001), Laitner (2000), Acemoglu and Guerrieri (2008), and Desmet and Rossi-Hansberg (2009).

${ }^{3}$ Also, see Ju, Lin and Wang (2009) for an $n$-sector model.

${ }^{4}$ Three differences in modeling and calibration are: a) BGV set several preference parameters from the literature, while we estimate the parameters. b) BGV employ a value-added framework, which is not consistent with the measurement of international trade in the data. c) We evaluate the role of non-homothetic preferences.

${ }^{5}$ There are several other differences. Sposi (2012) does not examine the effects of changes in non-tariff trade costs, nor the importance of non-homothetic preferences. On the other hand, his model allows for non-zero trade deficits and includes more than two countries.

${ }^{6}$ Other quantitative open economy models of structural change include Coleman (2007), Galor and Mountford (2008), Reyes-Heroles (2012), Stefanski (2012), Swiecki (2012), Ungor (2012). Coleman (2007) uses a multi-country Heckscher-Ohlin-Ricardo framework to study the effect of a large emerging market
} 
The paper is organized as follows. Section 2 lays out the model, and Section 3 uses a simplified version to illustrate the key impacts of an open economy on structural change. Section 4 presents the calibration and studies the importance of the two key sources of shocks and the two key transmission mechanisms (openness and non-homothetic preferences). Section 5 concludes.

\section{Model}

Our model has two countries and three sectors, and it includes non-unitary income and substitution elasticities of demand and sector-specific productivity growth to allow both Engel's law and the Baumol effect to operate. We introduce international trade based on the Ricardian motive, following Eaton and Kortum (2002). Agriculture and manufacturing goods are tradable and the services good is non-tradable. In each sector, production uses both labor and intermediate inputs. Productivity and trade costs change at different rates across sectors and countries; these forces drive structural change. Trade is balanced each period. (We omit the time subscript unless needed.)

\subsection{Technologies}

There is a continuum of goods in the agriculture $(a)$, manufacturing $(m)$ and services $(s)$ sectors. Each country possesses technologies for producing all the goods in all sectors. The production function for good $z \in[0,1]$ in sector $k \in\{a, m, s\}$ of country $i$ is

$$
Y_{i k}(z)=A_{i k}(z) L_{i k}(z)^{\lambda_{k}}\left[\Pi_{n=a, m, s} M_{i k n}^{\gamma_{k n}}(z)\right]^{1-\lambda_{k}}
$$

country on other countries' GDPs and welfare. Galor and Mountford (2008) study the effect of trade on fertility and population growth, and on human capital acquisition. Reyes-Heroles (2012) studies structural transformation in the United States. Stefanski (2012) studies the effect of structural transformation of India and China on oil prices. Swiecki (2012) employs a multi-sector model that includes intersectoral distortions and evaluates the welfare gains from trade. Ungor (2012) uses a two-sector model to study the effects of China's growth on de-industrialization of the United States. 
where $Y_{i k}(z)$ denotes output, $A_{i k}(z)$ denotes exogenous productivity, $L_{i k}(z)$ denotes labor, and $M_{i k n}(z)$ denotes sector- $n$ composite goods used as intermediates in the production of the sector $k$ good. The parameter $\lambda_{k}$ denotes the value-added share in production, and $\gamma_{k n}$ denotes the share of intermediate inputs sourced from sector $n$.

$A_{i k}(z)$ is the realization of a random variable $Z_{i k}$ drawn from the cumulative distribution function $F_{i k}(A)=\operatorname{Pr}\left[Z_{i k} \leq A\right]$. Following Eaton and Kortum (2002), we assume that $F_{i k}(A)$ is a Fréchet distribution: $F_{i k}(A)=e^{-T_{i k} A^{-\theta}}$, where $T_{i k}>0$ and $\theta>1$. The larger is $T_{i k}$, the greater the mean efficiency for any good $z$. The larger is $\theta$, the lower the heterogeneity or variance of $Z_{i k} !^{7}$ We assume that the productivity is drawn each period 8

When agriculture or manufacturing goods are shipped abroad, they incur trade costs, which include tariffs, transportation costs, and other barriers to trade. We model these costs as iceberg costs. Specifically, if one unit of manufacturing good $z$ is shipped from country $j$, then $\frac{1}{\tau_{i j m}}$ units arrive in country $i$. We assume that trade costs within a country are zero, i.e., $\tau_{i i a}=\tau_{i i m}=1$.

Goods markets are perfectly competitive; goods prices are determined by marginal costs of production. The cost of an input bundle in sector $k$ is $v_{i k}=w_{i}^{\lambda_{k}}\left(\prod_{n=a, m, s}\left(P_{i n}\right)^{\gamma_{k n}}\right)^{1-\lambda_{k}}$, which is the same within a sector, but varies across sectors given different input shares across sectors. The price of the services good $z$ is $p_{i s}(z)=\frac{v_{i s}}{A_{i s}(z)}$. For tradable goods, the price at which country $j$ can supply tradable good $z$ in sector $k$ to country $i$ equals $p_{i j k}(z)=\frac{\tau_{i j k} v_{j k}}{A_{j k}(z)}$. Since buyers will select to buy from the cheapest source, the actual price for this good in country $i$ is $p_{i k}(z)=\min \left\{p_{i 1 k}(z), p_{i 2 k}(z)\right\}$.

The composite good in each sector $Q_{i k}$ is an aggregate of the individual goods $Q_{i k}(z)$ :

$$
Q_{i k}=\left(\int_{0}^{1} Q_{i k}(z)^{\frac{\eta-1}{\eta}} d z\right)^{\frac{\eta}{\eta-1}}
$$

\footnotetext{
${ }^{7} Z_{i k}$ has geometric mean $e^{\frac{\gamma}{\theta}} T_{i k}^{\frac{1}{\theta}}$ and its $\log$ has a standard deviation $\frac{\pi}{\theta \sqrt{6}}$, where $\gamma$ is Euler's constant.

${ }^{8}$ Alternatively, we could assume that the productivity is drawn once in the initial period, and as the T's change over time, the productivity relative to $T$ remains constant.
} 
where the elasticity of substitution across goods within a sector is $\eta>0$. For the services sector, each good $z$ is produced locally, while for the tradable sectors, each good $z$ is either produced locally or imported from abroad. The composite sectoral goods are used in domestic final consumption, $C_{i k}$, and domestic production as intermediate inputs.

Under the Fréchet distribution of productivities, Eaton and Kortum (2002) show that the price of tradable composite good $k \in\{a, m\}$ in country $i$ is $P_{i k}=\Gamma\left(\Phi_{i k}\right)^{-\frac{1}{\theta}}$, where the constant $\Gamma$ is the Gamma function evaluated at $\left(1-\frac{\eta-1}{\theta}\right)^{\frac{1}{1-\eta}}$, and $\Phi_{i k}=T_{1 k}\left(v_{1 k} \tau_{i 1 k}\right)^{-\theta}+$ $T_{2 k}\left(v_{2 k} \tau_{i 2 k}\right)^{-\theta} . \Phi_{i k}$ summarizes country $i$ 's access to global production technologies in sector $k$ scaled by the relevant unit costs of inputs and trade costs.9 For the services composite good, the price is $P_{i s}=\Gamma\left(\Phi_{i s}\right)^{-\frac{1}{\theta}}$, where $\Phi_{i s}=T_{i s}\left(v_{i s}\right)^{-\theta}$.

The share of country $j$ 's expenditure on sector- $k$ goods from country $i, \pi_{j i k}$, equals the probability of importing sector- $k$ goods from country $i$ in country $j$, and is given by

$$
\pi_{j i k}=\frac{T_{i k}\left(v_{i k} \tau_{j i k}\right)^{-\theta}}{\Phi_{j k}} .
$$

Equation (2) shows how a higher average productivity, a lower unit cost of input bundles, and a lower trade cost in country $i$ translate into a greater import share by country $j$.

\section{$2.2 \quad$ Preferences}

Period utility of the representative household in country $i$ is given by

$$
U\left(C_{i a}, C_{i m}, C_{i s}\right)=\left[\omega_{a}^{\frac{1}{\epsilon}}\left(C_{i a}-\bar{C}_{a}\right)^{\frac{\epsilon-1}{\epsilon}}+\omega_{m}^{\frac{1}{\epsilon}}\left(C_{i m}-\bar{C}_{m}\right)^{\frac{\epsilon-1}{\epsilon}}+\omega_{s}^{\frac{1}{\epsilon}}\left(C_{i s}-\bar{C}_{s}\right)^{\frac{\epsilon-1}{\epsilon}}\right]^{\frac{\epsilon}{\epsilon-1}}
$$

where for each sector $k \in\{a, m, s\}, C_{i k}$ is consumption of sector- $k$ composite goods, and $\bar{C}_{k}$ is the subsistence requirement for sector- $k$ composite goods. A positive value of $\bar{C}_{k}$ generates an income elasticity of demand for the sector $k$ goods less than one. The preference

\footnotetext{
${ }^{9}$ We need to assume $\eta-1<\theta$ to have a well-defined price index. Under this assumption, the parameter $\eta$, which governs the elasticity of substitution across goods within a sector, can be ignored because it appears only in the constant term $\Gamma$.
} 
share parameters $\omega_{k}$ 's are positive and sum to one across sectors. The elasticity of substitution across sectoral composite goods is $\epsilon>0$. If $\epsilon>1$, the sectoral composite goods are substitutes, and if $\epsilon \leq 1$, the sectoral composite goods are complements.

The representative household maximizes his/her utility (3) subject to the following budget constraint in each period:

$$
P_{i a} C_{i a}+P_{i m} C_{i m}+P_{i s} C_{i s}=w_{i}
$$

where $w_{i}$ and $P_{i k}$ denote the wage rate and the price of the sector- $k$ composite good, respectively. The household supplies its unit labor endowment inelastically and spends all labor income. The budget constraints (4) ensure that balanced trade holds period-by-period.

\subsection{Equilibrium}

All factor and goods markets are characterized by perfect competition. Labor is perfectly mobile across sectors within a country, but immobile across countries. Let $L_{i}$ denote total labor endowment in country $i$ and $L_{i k}$ denote labor employed in sector $k$. The factor market clearing conditions in each period are given by

$$
L_{i}=L_{i s}+L_{i m}+L_{i a}
$$

We next characterize the good market clearing condition. For each sector $k$, we have

$$
Q_{i k}=C_{i k}+\sum_{n=a, m}\left(1-\lambda_{n}\right) \gamma_{n k} \sum_{j=1,2} \frac{\pi_{j i n} P_{j n} Q_{j n}}{P_{i k}}+\left(1-\lambda_{s}\right) \gamma_{s k} \frac{P_{i s} Q_{i s}}{P_{i k}}
$$

That is, the quantity of sector- $k$ composite goods produced in country $i, Q_{i k}$, is the sum of the quantity demanded (i) for domestic final consumption $C_{i k}$; (ii) for use as intermediate inputs

in the production of domestic tradable goods, $\sum_{n=a, m}\left(1-\lambda_{n}\right) \gamma_{n k} \sum_{j=1,2} \frac{\pi_{j i n} P_{j n} Q_{j n}}{P_{i k}}$; and (iii) for use as intermediate inputs in the production of domestic services goods, $\left(1-\lambda_{s}\right) \gamma_{s k} \frac{P_{i s} Q_{i s}}{P_{i k}}$. 
These good market clearing conditions demonstrate that our model captures two key features of the world economy. First, the model allows trade in intermediates, as much of world trade is in intermediates. Second, the model captures two-way input linkages across sectors.

We define a competitive equilibrium of our model economy with country-specific labor endowment processes $\left\{L_{i}\right\}$, trade cost processes $\left\{\tau_{i j a}, \tau_{i j m}\right\}$, productivity processes $\left\{T_{i a}, T_{i m}, T_{i s}\right\}$ and common structural parameters $\left\{\epsilon, \eta, \theta,\left\{\lambda_{k}, \gamma_{k n}, \bar{C}_{k}, \omega_{k}\right\}_{n, k=a, m, s}\right\}$ as follows.

Definition 1. A competitive equilibrium is a sequence of goods and factor prices $\left\{P_{i a}\right.$, $\left.P_{i m}, P_{i s}, w_{i}\right\}_{i=1,2}$, allocations $\left\{L_{i a}, L_{i m}, L_{i s}, Q_{i a}, Q_{i m}, Q_{i s}, C_{i a}, C_{i m}, C_{i s}\right\}_{i=1,2}$, and trade

shares $\left\{\pi_{i j a}, \pi_{i j m}\right\}_{i, j=1,2}$, such that, given prices, the allocations solve the firms' maximization problems associated with technologies (1) and the household's maximization problem characterized by (3)-(4), and satisfy the market clearing conditions $(5)-(6)$.

\section{How Trade Impacts Structural Change}

This section illustrates the mechanisms through which trade impacts the patterns of structural change - sectoral labor shares - in an open economy. To deliver the results transparently, we abstract from intermediate input usage by assuming $\lambda_{k}=1$ for all $k$. We compare the patterns of structural change in an open economy with those in a closed economy, and highlight two channels - the expenditure and net export channels - through which trade impacts structural change.

\subsection{Structural Change in a Closed Economy}

We begin our analysis of the model by developing the pattern of structural change in a closed economy, which is a special case of our model in which the trade costs are infinitely high. We use the superscript $c$ to denote the relevant variables in the closed economy. Under autarky, all goods are produced domestically. It is straightforward to show for country $i$ and each 
period, the sectoral composite good prices are given by

$$
\frac{P_{i a}^{c}}{w_{i}^{c}}=\frac{1}{A_{i a}}, \quad \frac{P_{i m}^{c}}{w_{i}^{c}}=\frac{1}{A_{i m}}, \quad \frac{P_{i s}^{c}}{w_{i}^{c}}=\frac{1}{A_{i s}},
$$

where $A_{i k}=\frac{T_{i k}^{\frac{1}{\theta}}}{\Gamma}$.

The feasibility conditions imply that the sectoral labor share equals the sectoral expenditure share $\sqrt[10]{10}$ For each sector $k \in\{a, m, s\}$, we have

$$
l_{i k}^{c}=\frac{L_{i k}^{c}}{L_{i}}=\frac{w_{i}^{c} L_{i k}^{c}}{w_{i}^{c} L_{i}}=\frac{P_{i k}^{c} C_{i k}^{c}}{w_{i}^{c} L_{i}} \equiv X_{i k}^{c}=\omega_{k}\left(\frac{P_{i k}^{c}}{P_{i}^{c}}\right)^{1-\epsilon}\left(1-\sum_{n} \frac{P_{i n}^{c} \bar{C}_{n}}{w_{i}^{c}}\right)+\frac{P_{i k}^{c} \bar{C}_{k}}{w_{i}^{c}},
$$

where the aggregate price $P_{i}^{c}$ equals $\left(\sum_{k} \omega_{k}\left(P_{i k}^{c}\right)^{1-\epsilon}\right)^{\frac{1}{1-\epsilon}}$. Clearly, non-unitary income and non-unitary substitution elasticities allow changing relative prices (relative productivities) and changing income to impact structural change in autarky.

If $\bar{C}_{k}$ in all sectors is set to zero, preferences become homothetic, and the implications are similar to those in Ngai and Pissarides (2007):

$$
l_{i k}^{c} \equiv X_{i k}^{c}=\omega_{k}\left(\frac{P_{i k}^{c}}{P_{i}^{c}}\right)^{1-\epsilon}
$$

Turning to dynamics, let $\hat{Z}$ denote the $\log$ growth rate of variable $Z$. Then, for any period $t$, we have

$$
\hat{l}_{i k t}^{c}=\hat{X}_{i k t}^{c}=(1-\epsilon)\left(\hat{P}_{i k t}^{c}-\hat{P}_{i t}^{c}\right)=(\epsilon-1)\left(\hat{A}_{i k t}-\hat{A}_{i t}^{c}\right)
$$

where $\hat{A}_{i t}^{c}=\sum_{k} X_{i k t}^{c} \hat{A}_{i k t}$. Thus, the elasticity of substitution links changes in sectoral labor shares to changes in sectoral relative prices and productivities. In the Cobb-Douglas case $(\epsilon=1)$, there is no structural change: sectoral expenditure and labor shares are constant over time. In an empirically relevant case with $\epsilon<1$, a sector with rising relative productivities experiences declining relative prices, expenditure shares, and labor shares over time. Labor

\footnotetext{
${ }^{10}$ The sectoral labor share equals the sectoral expenditure share even in a framework with capital and intermediate goods, as long as the factor intensity in the production function is identical across sectors.
} 
moves from high productivity growth sectors to low productivity growth sectors. If the manufacturing sector has the fastest productivity growth among the three sectors, its labor share declines over time. This implication is consistent with the post-war experience of many developed countries. However, in many developing countries, the manufacturing sector has both the fastest growth in productivity and a rising labor share: clearly at odds with the implications of the closed economy model ${ }^{11}$

\subsection{Structural Change in an Open Economy}

We now turn to an open economy and begin by defining comparative advantage. Country $i$ has a comparative advantage in manufacturing if and only if $\frac{A_{i m}}{A_{j m} / \tau_{i j m}}>\frac{A_{i a}}{A_{j a} / \tau_{i j a}}$. Our definition is thus the traditional definition augmented by trade costs 12 The comparative advantage patterns determine intra-sector trade patterns. If country 1 has a comparative advantage in manufacturing, equation (2) implies that $\pi_{11 m}>\pi_{11 a}$. Intuitively, a greater share of spending is on domestic goods in the comparative advantage sector.

First, consider the impact of an open economy on sectoral prices. The services good price in country $i$ relative to wage is $\frac{P_{i s}}{w_{i}}=\frac{1}{A_{i s}}$, which is the same as under autarky. The price of tradable composite good $k$ relative to wage is

$$
\frac{P_{i k}}{w_{i}}=\frac{1}{A_{i k}}\left[1+\left(\frac{\tau_{i j k} w_{j}}{A_{j k}} \frac{A_{i k}}{w_{i}}\right)^{-\theta}\right]^{-\frac{1}{\theta}}=\frac{\pi_{i i k}^{\frac{1}{\theta}}}{A_{i k}} .
$$

Comparing equation 10 to (7), one can see that $\frac{P_{i k}}{w_{i}}<\frac{P_{i k}^{c}}{w_{i}^{c}}$ because $\pi_{i i k}<1$. The lower

\footnotetext{
${ }^{11}$ We examine the 19 countries in Asia and Latin America from the GGDC 10-sector data base, and compute sectoral employment shares and growth in sectoral real-value added per worker for each country. Of the 19, 10 had the highest productivity growth in manufacturing, and of these 10, 7 countries (Indonesia, Japan, Korea, Singapore, Thailand, Taiwan, and Venezuela) experience a higher manufacturing employment share over most of the sample period than in the initial year.

${ }^{12}$ Hence, it is possible for a country to have a relative disadvantage in manufacturing from the productivities alone, but, owing to sufficiently small manufacturing trade costs, an overall comparative advantage in manufacturing. See Deardorff (2004) for further discussion on the topic of comparative advantage in the presence of trade costs. In this section, we restrict our attention to cases in which one country has a comparative advantage in manufacturing and the other country has a comparative advantage in agriculture, which is a restriction that trade costs cannot be too different across sectors and countries.
} 
is the sectoral expenditure share on domestic goods, the lower is the sectoral price. Trade essentially allows countries to enlarge their effective technologies in the tradable sectors, thus leading to lower prices, especially in the comparative disadvantage sector. The aggregate price level relative to the wage rate $\frac{P_{i}}{w_{i}}$ is also lower in the open economy than in autarky, which is consistent with the well-known result from classical trade theory that there are gains from trade.13

Next consider the impact of trade on expenditure shares. The expression of the expenditure share is the same in the open economy as in the closed economy, and is given by equation (8). However, openness affects the expenditure shares through its impact on relative prices, discussed above, and also its impact on income.

Now we turn to the sectoral labor allocations. Because services sector goods are nontradable, $l_{i s}=X_{i s}$, as in the closed economy. Nonetheless, trade impacts the services labor share by affecting the services expenditure share.

For the tradable sectors, country 1's income from sector $k$ equals expenditures of both countries on its sector- $k$ goods: $w_{1} L_{1 k}=\pi_{11 k} P_{1 k} C_{1 k}+\pi_{21 k} P_{2 k} C_{2 k}$, implying

$$
l_{1 k}=\frac{L_{1 k}}{L_{1}}=\pi_{11 k} X_{1 k}+\pi_{21 k} X_{2 k} \frac{w_{2} L_{2}}{w_{1} L_{1}} .
$$

Three forces determine country 1's labor share in sector $k$. First, it depends on the expenditure share of each country on sector $k$ goods, $X_{1 k}$ and $X_{2 k}$. It also depends on the extent of specialization, $\pi_{11 k}$ and $\pi_{21 k}$. Finally, it depends on the relative size of the two economies.

Alternatively, substituting $1-\pi_{12 k}$ for $\pi_{11 k}$ in equation (11) gives

$$
l_{1 k}=X_{1 k}+\frac{\pi_{21 k} X_{2 k} w_{2} L_{2}-\pi_{12 k} X_{1 k} w_{1} L_{1}}{w_{1} L_{1}}=X_{1 k}+N_{1 k}
$$

where $N_{1 k}$ denotes the sectoral net export share of total GDP in country 1 . Thus, the tight link that binds sectoral demand and production in the closed economy does not hold in the

$13 \frac{P_{i}}{w_{i}}$ is the reciprocal of the real wage or the real purchasing power of each country's income. 
open economy. The net export channel, $N_{1 k}$, captures the direct contribution of international trade to structural change. In addition, trade contributes indirectly to structural change through the expenditure channel, $X_{1 k}$.

Consider the dynamics of structural change in an open economy. For services, as in the closed economy, the growth rate of the labor share equals the growth rate of the expenditure

share: $\hat{l}_{i s t}=\hat{X}_{i s t}$. However, because openness affects the growth rate of overall income and of the services relative price, trade will affect the growth rate of the services expenditure share and labor share. The growth rate of the labor share of tradable sector $k$ in country $i$ is given by

$$
\hat{l}_{i k t}=\frac{X_{i k t}}{l_{i k t}} \hat{X}_{i k t}+\frac{N_{i k t}}{l_{i k t}} \hat{N}_{i k t}
$$

which differs from (9) by the addition of the net export term. Changes in both expenditure and net export shares affect structural change.

\subsubsection{The Net Export Channel}

The cleanest way to see the direct contribution of trade to the sectoral labor shares is with unit income and substitution elasticities of demand. In this case, the expenditure share of sector $k$ is simply $\omega_{k}$ and constant over time. In autarky, the labor share is thus also constant; asymmetric productivity growth and the evolution of income play no role in structure change. In an open economy, the services labor share is $\omega_{s}$, as in autarky. The labor share of tradable sector $k \in\{a, m\}$ is $\omega_{k}+N_{i k}$ in the open economy. $N_{i k}$ captures exactly the impact of trade on structural change. We now derive a natural, but important, implication of the model: a country will experience a net export surplus in its comparative advantage sector. Hence, when a country opens up to trade, labor moves from its comparative disadvantage sector to its comparative advantage sector.

Assume that country 1 (2) has a comparative advantage in manufacturing (agriculture). The trade balance of sector $k$ in country 1 is $N X_{1 k}=\pi_{21 k} \omega_{k} w_{2} L_{2}-\pi_{12 k} \omega_{k} w_{1} L_{1}$, where the expenditure share is $\omega_{k}$ in both countries. The pattern of comparative advantage implies 
$\pi_{21 m}>\pi_{21 a}$ and $\pi_{12 m}<\pi_{12 a}$. If country 1 ran a trade deficit in the manufacturing sector, it cannot run a trade deficit in the agriculture sector, otherwise it would violate the balanced trade condition. Hence, it must be the case that $N X_{1 m}>0$ and $N X_{1 a}<0.14$

We describe two scenarios in which the presence of trade can generate a hump-shaped pattern in the manufacturing employment share. In the first scenario, a country with a comparative advantage in manufacturing experiences both relative and absolute productivity growth in manufacturing over time. Because of the relative productivity growth, the country's manufacturing labor share rises initially as it supplies an increasing share of world demand for manufacturing products. As time passes, the continuing increase in absolute productivity implies that, despite the increasing net export surplus, fewer workers are needed to produce the manufactured goods. Eventually, the latter effect dominates, and the manufacturing labor share declines 15

In the second scenario, the primary driving force is declining trade costs over time. As trade costs decline, each country's comparative advantage is increasingly revealed, and there is increased specialization. A country with a comparative advantage in manufacturing experiences a rising manufacturing employment share initially. If the country is small, its relative wage increases over time, because the gains from trade are larger for smaller countries. Consequently, the relative purchasing power of its trading partner declines, which reduces the amount of its labor needed to satisfy foreign demand for manufactured goods. As long as its relative wage continues to increase, this relative purchasing power effect will eventually dominate, and the manufacturing labor share will peak and then decline.

\subsubsection{Adding Expenditure Channel}

We now consider the impact of trade on expenditure shares by allowing either the income or substitution elasticities to be different from one. When the income elasticities are different from one across sectors, real income levels impact the expenditure share as shown in Equation

\footnotetext{
${ }^{14}$ This result can also be established for CES preferences and free trade.

${ }^{15}$ The conditions under which productivity growth is sufficiently high are available in the Appendix.
} 
(8). In the open economy, trade increases real income in both countries, reinforcing incomeinduced labor reallocations.

Equation (8) also shows that when the substitution elasticity differs from one, relative prices impact the expenditure shares. Focusing on the Baumol case, $\epsilon<1$, in both countries, $\frac{P_{i s}}{P_{i}}$ is higher in the open economy; hence, the services expenditure share and labor share are higher in the open economy. For the sector in which country $i$ has a comparative disadvantage, its price relative to the aggregate price is lower, and its expenditure share is lower in the open economy. ${ }^{16}$ Suppose manufacturing has the highest productivity growth; then, the expenditure channel would imply a declining manufacturing labor share. For the model to generate a rising manufacturing labor share, the net export channel needs to be sufficiently strong initially to more than offset the expenditure channel. However, as in the unitary elasticity case, over time, the net export channel diminishes, and the expenditure channel begins to dominate, leading to declining manufacturing labor shares.

In this section, we have used our model to demonstrate the multiple channels through which an open economy can affect a country's structural change. All the channels start from comparative advantage and specialization. These starting forces affect relative prices, which then feed into expenditure shares and labor shares. In addition, specialization by itself leads to reallocation of labor across sectors. Finally, these forces lead to higher income, which, in a world with non-homothetic preferences, also affects labor shares. Over time, structural change is driven by productivity growth and by changes in trade costs. Because these shocks affect comparative advantage and specialization, their ultimate impact is different in an open economy from a closed economy. It remains to be seen whether an open economy framework is quantitatively relevant, and which channels and shocks are quantitatively important. The next section addresses these questions.

\footnotetext{
${ }^{16}$ In the comparative advantage sector, the sectoral relative price may or may not be lower in the open economy, hence, the effect of trade on the expenditure share cannot be signed.
} 


\section{Quantitative Analysis}

We now employ our model to quantitatively analyze the importance of openness in South Korea's structural change between 1971 and 2005. As Figure 1 shows, Korea experienced substantial structural change during this 35-year period. The agriculture labor share declined sharply and essentially monotonically from 0.48 to 0.09 , and the services labor share rose sharply and essentially monotonically from 0.40 to 0.73 . In addition, the manufacturing labor share displayed the hump-shaped pattern: rising from 0.13 in 1971 to 0.27 by 1989 and then declining to 0.17 by 2005 . Explaining these dynamics over time is the challenge posed to our model. The first subsection discusses how we calibrate the model. The second subsection presents simulation results of our model, including counterfactuals designed to assess the relative importance of the two main shocks in our model, changes in trade costs and in TFP, as well as the importance of two key transmission channels, the open economy and non-homothetic preferences.

\subsection{Calibration}

We calibrate our two-country model with South Korea as one country and the rest of the world (ROW) as the other country. The ROW consists of most of South Korea's (hereafter, Korea) important trading partners in this period, and includes the G7 countries, other OECD countries, and several oil-producing countries in the Middle East and Latin America. These countries accounted for, on average, two-thirds of Korea's trade during this time period. Some countries were excluded because of data availability issues or because they were not important in Korea's trade ${ }^{17}$ The list of countries is given in the Appendix.

We now describe our calibration of the preference parameters $\left\{\omega_{j}, \bar{C}_{j}, \epsilon\right\}$ and the production parameters $\left\{\lambda_{j}, \gamma_{j k}, \theta\right\}$. These parameters are assumed to be identical across countries and time invariant. Consistent with recent estimates by Simonovska and Waugh (2011), we

\footnotetext{
${ }^{17}$ Notably, China is excluded owing to lack of data, especially in the 1970s and 1980s. We discuss the possible role of China in the conclusion.
} 
set $\theta=4$. The other parameters are calibrated to Korean data. Much of the literature (e.g., Duarte and Restuccia 2010 and Herrendorf, Rogerson, and Valentinyi 2012) focuses on estimating $\bar{C}_{a}$ and $\bar{C}_{s}$. Following this convention, we set $\bar{C}_{m}=0$, which essentially implies that manufacturing's income elasticity of demand is close to one. Consistent with this assumption, we change the assignment of consumption of food, beverages, and tobacco from the manufacturing sector to the agriculture sector 18

For the preference parameters, we appeal to restrictions imposed by the intratemporal Euler equations governing sectoral consumption expenditure. Using the language of Herrendorf, Rogerson, and Valentinyi (HRV, 2012), we adopt the final consumption expenditure approach, which arises naturally from our model with intermediate inputs. We employ time-series data on Korean aggregate consumption expenditure $\left\{P_{t} C_{t}\right\}$, sectoral consumption expenditure shares $\left\{s_{j t}\right\}$, and sectoral prices $\left\{P_{j t}\right\}$ to estimate $\left\{\epsilon, \omega_{a}, \omega_{m}, \omega_{s}, \bar{C}_{a}, \bar{C}_{s}\right\}$ by minimizing the sum of squared deviations between the actual sectoral expenditure shares and the model-implied sectoral expenditure share given the observed sectoral prices and aggregate consumption expenditure:19

$$
\sum_{t} \sum_{j=a, m, s}\left[s_{j t}-\left(\frac{\omega_{j} P_{j t}^{1-\epsilon}}{P_{t}^{1-\epsilon}}\left(1-\sum_{k=a, m, s} \frac{P_{k t} \bar{C}_{k}}{P_{t} C_{t}}\right)+\frac{P_{j t} \bar{C}_{j}}{P_{t} C_{t}}\right)\right]^{2}
$$

subject to the constraints $\sum_{j} \omega_{j}=1$. This is also the estimating equation used in HRV. The estimated values (along with the other parameters) are reported in Table 1. The elasticity of substitution across sectors is 0.75 , and the subsistence parameter of the agriculture goods

\footnotetext{
${ }^{18}$ We adjust our trade, consumption, employment and production data so they are all consistent in terms of the sectors covered. The matching of detailed sectors into our three broad sectors is given in the appendix.

${ }^{19}$ See the appendix for the data sources for the sectoral consumption expenditure and price data, as well as the aggregate consumption data. We estimate these parameters over data from 1970-2010; we use a larger period than the period for our calibration to increase the number of observations. With three sectors, there are a total of 123 observations. The estimates over the period 1971-2005 are similar.
} 
is positive. The estimate for the services sector consumption parameter $\bar{C}_{s}$ is nearly 0.20

Turning to the production parameters, we use all input-output tables for Korea available in our sample period ${ }^{21}$ Specifically, the value added share $\lambda_{j}$ and the matrix of intermediate input linkages $\gamma_{j k}$ are computed directly from the input-output tables. We take a simple average across the tables, and report these values in Table 1.

We now describe the calibration of the time-varying exogenous variables and shocks. The primary exogenous variables are total labor in both Korea and the ROW. These variables are taken directly from the data; the appendix provides the data sources. The labor force grew at an average annual rate of 2.5 percent in Korea and 1.1 percent in the ROW over our sample period. The procedure for calibrating the productivity shocks and trade costs shocks for each sector, country, and year has three key parts. The first part involves the calibration of the initial year, 1971. As our main goal is to assess the importance of openness in explaining Korea's structural change over time, we calibrate the initial productivity and trade cost levels - three sectoral productivities and two sectoral trade costs in each country — to match the ROW and Korea's sectoral labor shares and sectoral trade shares in 1971.22 Because two sectoral labor shares automatically imply the third, we need two additional targets. We choose Korea's per capita income relative to the ROW in 1971, and Korea's agricultural subsistence expenditure as a share of total consumption expenditure. Table 1 provides the values of our targets.

The second part involves the calibration of the productivity shocks after the initial period. These shocks are constructed using the initial period sectoral productivity levels computed above, and sectoral productivity growth rates, which are constructed in two main steps. ${ }^{23}$ The first step arises from the fact that real sectoral gross output data do not exist for

\footnotetext{
${ }^{20}$ The elasticity of substitution across goods within a sector $\eta$ is set to 4 ; this parameter plays virtually no role in our model, as is the case with virtually all versions of the Eaton-Kortum model.

${ }^{21}$ The list of years is given in the Appendix.

${ }^{22}$ The sectoral import shares are Korea's sectoral imports from the ROW as a fraction of Korea's sectoral absorption. The sectoral export shares are Korea's sectoral exports to the ROW also expressed as a fraction of Korea's sectoral absorption.

${ }^{23}$ Further details on the construction of the productivities and the data sources are provided in the Appendix.
} 
a number of the countries that comprise the ROW. Annual input-output tables are also lacking. Consequently, the usual approach of constructing (gross output) productivities directly from the gross output production function cannot be performed. Instead, we use the model to derive the sectoral value-added production function, and we compute sectoral value-added productivity. Owing to the Cobb-Douglas functional form, the sectoral valueadded productivity is $A_{i k}^{\frac{1}{\lambda_{k}}}$, where $A_{i k}$ is gross output productivity for country $i$ and sector $k$. The second step arises from Waugh (2010) and Finicelli, Pagano and Sbracia (hereafter, FPS 2012), among others, who have shown that productivities computed in an open economy setting capture at least two forces, the fundamental productivity of firms within the country under autarky, and the additional productivity occurring from specialization in an open economy (trade selection). We need to compute the fundamental productivity. FPS derive a formula for adjusting the usual productivity measure for the specialization component to yield the fundamental productivity. We apply that formula, which yields our final estimates of sectoral gross output productivity or TFP. We calculate the growth rates of the sectoral TFPs and apply them to the initial period to get the sectoral TFP levels for 1972 onwards. ${ }^{24}$

The logged sectoral TFPs are shown in Figure 2, In the initial period, the ROW has higher TFP levels in all three sectors. The average TFP growth rates are 1.8 percent in agriculture, 2.2 percent in manufacturing, and 1.7 percent in services in Korea, and 1.2 percent in agriculture, 0.84 percent in manufacturing and 0.60 percent in services in the ROW. The average TFP growth rates are higher in Korea than in the ROW for all three sectors. Also, the manufacturing sector has the fastest TFP growth rate among the three sectors in Korea.

The third part involves calibrating the trade costs over time after the initial period. It is well known that the standard trade models can explain existing international trade flows only if unobserved trade costs, i.e., costs other than tariff barriers and transportation costs, are a multiple of observed trade costs. This is true under a wide range of elasticities of demand and

\footnotetext{
${ }^{24}$ Our approach will yield an estimate for TFP levels in the initial year, 1971; as a diagnostic, these can be compared to the ones we choose to match the labor shares, etc. They are close in relative magnitudes.
} 
substitution. Consequently, as our focus is on whether the model can explain the dynamics of Korea's labor shares, we calibrate the four sectoral trade costs to match the observed trade flows between Korea and the ROW over time: Korea's export and import shares with the ROW in manufacturing and agriculture. We solve for the trade costs jointly with solving the model. We interpret the model-implied trade costs as capturing transportation costs, tariffs, and any other costs that impede international trade ${ }^{25}$ The calibrated trade costs are shown in Figure 3, together with Korean sectoral import and export shares. The figure shows that trade costs from the ROW to Korea in both agriculture and manufacturing changed little over time, while trade costs from Korea to the ROW declined substantially. Panels (b) and (c) of Figure 3 show that the model does a good job of recovering the actual time path of the trade shares 26

\subsubsection{Calibration of Closed Economy Version of Model}

As we showed in section 3, openness operates as a transmission channel in at least two ways. First, openness via shocks to trade costs over time affect the evolution of structural change. Second, TFP shocks affect the economy differently in an open setting compared to a closed setting. To assess the quantitative effect of openness, we compare our results in an open economy setting with those in a closed economy setting in which the economy is subject to TFP shocks only. Our calibration of the closed economy is identical to that of the open economy except for the TFP shocks. For the initial period, we use a closed economy version of our model to calibrate, for Korea, three initial TFP levels to match two sectoral labor shares and agriculture subsistence expenditure as a share of total consumption expenditure in 1971. The TFP levels for subsequent years are computed in the same way as in the open economy model, but without the adjustment for trade selection. Our computations imply that Korea's average TFP growth rates for agriculture, manufacturing, and services are 2.2

\footnotetext{
${ }^{25}$ To the extent there is model misspecification and measurement error, it will show up in the trade costs.

${ }^{26}$ It is not a perfect fit, because the model assumes balanced trade.
} 
percent, 2.2 percent, and 1.7 percent, respectively 27

\subsection{Quantitative Results}

We now assess the quantitative importance of openness in structural change, and the roles of TFP shocks and trade cost shocks, in particular. We also assess the importance of nonhomothetic preferences as a transmission mechanism. To review the key features of our benchmark model, it has non-homothetic preferences, an elasticity of substitution across sectors less than one, asymmetric and growing TFP shocks over time, and changing trade costs over time.

\subsubsection{Main Results}

We first simulate the effects of the TFP shocks and trade cost shocks in our benchmark model. The implied sectoral labor shares are given in the blue dashed line in each panel of Figure 4. The red solid line shows the actual sectoral labor share. The model is able to capture the evolution of the agriculture and services labor shares over almost the entire time period. The model generates a decline in the agriculture labor share of slightly more than the actual decline, and an increase in the services labor share of about 85 percent of the actual rise in the services labor share. Turning to manufacturing, the model is able to generate an increase in the manufacturing labor share of 0.13 to 0.24 - close to the actual peak share of 0.27 - in the first half of the time period. However, subsequently the implied manufacturing labor share stays relatively flat, instead of declining as it does in the data. Hence, the model is able to replicate only the rising part of the hump-shaped pattern. Overall, the fit of our benchmark model is quite good, although it is not able to capture the declining part of Korea's manufacturing hump pattern.

\footnotetext{
${ }^{27}$ The difference between the open and closed economy TFP growth rates stems from the evolution of $\pi_{i i}$ over time. In particular, as discussed in the Appendix, if $\pi_{i i}$ is increasing over time, as it is in agriculture, then the growth rate of the (fundamental) open economy TFP will be lower than the growth rate of the closed economy TFP.
} 
To assess the importance of openness, we also simulate the model under a closed economy in which there are only TFP shocks. The model's implications for Korea's sectoral labor shares are shown as the gray dotted lines in Figure 4. Panels (a) and (c) show that the closed economy model also generates a substantial decline in the agricultural labor share and a substantial increase in the services labor share. However, the magnitudes of the changes are smaller than in the benchmark model. The closed economy model explains only 62 percent of the actual decline in the agriculture labor share and about 67 percent of the actual increase in the services labor share. In terms of manufacturing, as panel (b) of Figure 4 shows, the model does not come close to generating either side of the hump. Rather, it generates only a slight increase over time ${ }^{28}$

We summarize the overall performance of the benchmark model and the closed economy model in explaining Korea's structural change by computing the root mean square error (RMSE) between the implied and observed labor shares. The RMSEs for agriculture, manufacturing and services in the open economy are: $0.059,0.037$, and 0.060 . With the closed economy model, the RMSEs are $0.10,0.079$, and 0.062 . Thus, introducing trade significantly improves the model fit to the data, particularly in agriculture and manufacturing. The overall RMSE across all sectors is 0.053 in the open economy model and 0.083 in the closed economy model; hence, the closed economy fit is about 60 percent worse.

What explains the substantially better performance of the benchmark model? Consider first the closed economy model results. The decline in the model-implied agriculture share stems largely from the interaction of growing per capita income (resulting from growing TFP in all three sectors), and the non-homothetic preferences. Korea's services labor share grows partly because of the interaction of a low productivity growth rate and the low sectoral elasticity of substitution - as Ngai and Pissarides (2007) show, this combination leads to an

\footnotetext{
${ }^{28}$ Duarte and Restuccia (2010) use a somewhat different closed economy model to examine the structural change of a number of countries, including Korea. We thank them for kindly providing their results for Korea. Our closed economy results are similar to theirs. Their model also implies a small change in the manufacturing labor share, and substantial changes in the agriculture and services labor shares. Compared to our closed economy model, their model generates a closer fit to agriculture and worse fit for services.
} 
increasing sectoral labor share - but primarily because it needs to absorb the labor leaving the agricultural sector. Finally, manufacturing is subject to two forces that largely cancel. The first force is that it absorbs labor leaving the agriculture sector. The second force is the tendency to shrink because it has the highest productivity growth rate.

In an open economy, three additional forces lead to a larger response in the two tradable sectors, agriculture and manufacturing. First, the patterns of initial TFP and trade costs suggest that Korea had a comparative advantage in manufacturing; moreover, Korea's manufacturing TFP grew at a faster rate than agriculture's TFP. Second, the trade costs facing Korea's exporters declined over time, and more rapidly in manufacturing than in agriculture. Korea's comparative advantage in manufacturing becomes more "revealed," thus leading to more specialization and labor in manufacturing, and less in agriculture. The first force, in conjunction with a sectoral elasticity of substitution less than one, and the second force are evidently sufficient to generate a rise in the manufacturing labor share. Essentially, Korea is able to employ more workers in manufacturing, because expanding export markets more than offset the declining need for labor to satisfy domestic demand. The opposite is true for agriculture, leading to a decline in its share. The third force is that trade leads to faster economic growth in Korea. Real income rises by a factor of eight in the open economy; it rises by a factor of seven in the closed economy. The faster growth of real income strengthens the non-homothetic preferences channel and leads to a larger decline in the agriculture labor share and a larger rise in the services labor share.

The combination of all three forces leads to a significantly larger increase in the manufacturing labor share (more than 10 percentage points), a significantly larger decrease in the agriculture labor share (about 15 percentage points), and a larger increase in the services labor share (about 6 percentage points), than in the closed economy model. All three changes lead to a closer fit of the open economy model to the data. ${ }^{29}$

\footnotetext{
${ }^{29}$ Do our results suggest that Buera and Kaboski (2009), who find that a closed economy framework with non-homothetic preferences and asymmetric productivity growth cannot explain the movement of U.S. value-added shares in services and manufacturing after 1960, should have employed an open economy model? On the one hand we would say, yes; on the other hand, clearly trade has not been as important for the U.S.
} 
To understand better the results for manufacturing, we employ a decomposition of the manufacturing labor share into an expenditure channel and a net export channel, analogous to that in equation (12) ${ }^{30}$ Full details of the decomposition, which includes details for intermediate goods and non-homothetic preferences, are given in the Appendix. Our decomposition shows that, over our entire sample period, the expenditure channel accounts for about 80 percent of the model-implied manufacturing labor share, with the net export channel accounting for the remainder 31 However, if we trace the contribution of the net export channel over time, we see that this channel's contribution to the manufacturing labor share rose fairly steadily from -2.5 percentage points in 1971 to 6 percentage points in 2005 . Thus, the net export channel accounts for about $2 / 3$ of the increase in the model-implied manufacturing labor share during our sample period. The expenditure channel also increases steadily over the sample period by about three percentage points; this suggests that income effects from non-homothetic preferences that lead to more employment in manufacturing are stronger than relative price and substitution effects that lead to less employment in manufacturing. Because both channels increase over the entire sample period, they are both "responsible" for the model's inability to generate the downward portion of the manufacturing hump in the data.

Our analysis focuses on labor shares as a measure of structural change. It is also common to examine output shares. Because we did not use output shares to calibrate our model, one diagnostic of the model is to assess how it performs in terms of initial year output shares, as well as the dynamics of output shares over time. Figure 5 shows that for agriculture, the benchmark model over-predicts the initial output share quite substantially, but the dynamics over time are quite strong, so that by 2005 , the model-implied labor share is quite close to the actual share. For manufacturing, the model and data fit very closely in both the initial output share and the evolution over time; indeed, they fit more closely than do the labor

\footnotetext{
as it has been for Korea.

${ }^{30}$ We thank the referee for this suggestion.

${ }^{31}$ As we have discussed, the net export channel is only one way for openness to affect structural change, because part of the effect of increased openness is to change relative prices, which then affects expenditures.
} 
shares. Finally, the model under-predicts the initial services output share, but similar to agriculture it catches up over time, so that by 2005, the model and data line up closely. The figure also shows the closed economy implications. Other than for services, the fit is quite poor. Overall, we find that our benchmark model does a good job in matching the dynamics of the sectoral output shares.

\subsubsection{The Role of TFP Shocks versus Trade Cost Shocks}

In the benchmark analysis, both the TFP and trade cost series vary over time. In this section we quantify the contribution of each set of shocks to Korea's structural change. To do so, we conduct two counterfactual experiments. In the first experiment, we set all sectoral TFP series constant at their initial levels, and examine the effects of varying trade costs alone. In the second experiment, we set the sectoral trade costs constant at the initial levels, and examine the effects of varying TFPs alone. All other exogenous variables and parameter values are the same as in the benchmark model.

The green dashed line in Figure 6 illustrates the results of the first experiment. For comparison, the benchmark model results are illustrated with the blue dashed line. In addition, results from the closed economy version of this experiment — they are trivially zero, because TFP is constant, and in a closed economy, trade costs do not change are illustrated by the gray line. Beginning with the left panel, the figure shows that the agriculture labor share declines by a little more than 10 percentage points or about onefourth of the actual decline. This is not insignificant, but the figure illustrates indirectly the importance of TFP in driving income growth and the consequent re-allocation of labor away from agriculture. The middle panel shows that manufacturing rises by about 10 percentage points; this represents more than half of the increase generated by the benchmark model. Comparing this experiment to the benchmark model, then, suggests that changes in trade costs are more important for manufacturing than agriculture. The right panel shows that the services sector labor share increases by little, less than 5 percentage points. This is the 
flip side of the small decline in the agriculture labor share.

The green dashed line in Figure 7 illustrates the results of the second experiment. The benchmark model results and the closed economy results are shown with the blue dashed line and the gray line, respectively. All three panels show that TFP shocks contribute significantly to structural change. Note that the closed economy results indicate that TFP shocks exert a large effect on agriculture and services, but a small effect on manufacturing. The figure also shows that for manufacturing and agriculture, TFP shocks exert quantitatively significant effects in an open economy, as captured by the gap between the green and gray lines ${ }^{32}$ In particular, agriculture's labor share falls by more, and manufacturing's labor share rises by more than in the closed economy. The services labor share is about the same ${ }^{33}$ Thus, variation in each set of shocks is quantitatively significant in explaining Korea's structural change over time. TFP shocks matter more than trade cost shocks for services and agriculture, while both shocks are quantitatively important for manufacturing and agriculture. Moreover, for both shocks, trade serves as an effective transmission mechanism that enables the open economy to outperform the closed economy.

\subsubsection{The Role of Non-homothetic Preferences}

The above simulations and experiments were all conducted under non-homothetic preferences. These preferences are widely thought to be the most important transmission mechanism for structural change; however, underlying much of this thinking is an assumption of a closed economy setting. We now examine the importance of non-homothetic preferences in our open economy setting. To do so, we set $\bar{C}_{a}$ to zero, which makes preferences homothetic, and we re-calibrate the elasticity of substitution, $\epsilon$, and the share parameters $\omega_{a}, \omega_{m}$, and $\omega_{s}$ following the HRV approach, as before. The elasticity of substitution is calibrated to be

\footnotetext{
${ }^{32}$ Part of the gap is because the TFP shocks themselves are different, as described above, and part is because they operate differently in an open economy.

${ }^{33}$ Our assumption that services goods are non-traded implies that trade matters for this sector to the extent that relative prices and incomes change owing to the changing patterns of specialization. These forces do affect services, although to a lesser extent than the change in income arising from TFP growth.
} 
0.001, which is close to Leontief. This will lead to a greater role for relative prices ${ }^{34}$ In addition, the sectoral trade costs and TFPs are recalibrated in the same way as the benchmark calibration for both the open and closed economy models 35

The blue dashed line in figure 8 plots the model-implied sectoral labor shares under homothetic preferences. The panels show that even under these preferences, openness plays a key role: the agriculture labor share falls by about 20 percentage points, while the manufacturing labor share rises by almost 15 percentage points. On the other hand, services changes by little. However, compared to the benchmark results in Figure 4, we can see that for each sector the fit is worse under homothetic preferences, especially for services and also for agriculture. Manufacturing is little affected by the nature of the preferences. The RMSEs are $0.142,0.042$, and 0.151 for agriculture, manufacturing and services, respectively. The overall RMSE is 0.122 , as shown in Table 2. This exercise shows that leaving out the income effects induced by non-homothetic preferences significantly reduces the explanatory power of the model in explaining Korea's structural change ${ }^{36}$

Table 2 provides a crude assessment of the relative importance of non-homothetic preferences and the open economy. The closed economy model with homothetic preferences has a RMSE of 0.175. The open economy with non-homothetic preferences has an RMSE of 0.053. Inspection of the table suggests that about $1 / 3$ of the improvement in RMSE is because of the open economy and $2 / 3$ is because of non-homothetic preferences.

\footnotetext{
${ }^{34}$ The new share parameters are: $\omega_{a}=0.317 ; \omega_{m}=0.106 ; \omega_{s}=0.577$.

${ }^{35}$ Homothetic preferences allow us to normalize Korea's agriculture TFP level in the initial period to one. For the open economy model, the remaining five initial sectoral TFP levels and the four trade costs are calibrated to match the two labor shares in each country, four trade shares, and Korea's per capita income relative to the ROW in 1971. For the closed economy, the remaining two initial sectoral TFP levels in Korea are calibrated to match the two labor shares in 1971. For both the open and closed models, the subsequent TFP levels and trade costs are constructed the same way as in the benchmark calibration.

${ }^{36}$ In the closed economy, illustrated by the gray dashed line, there is almost no structural change. This result can be understood via Equation (9). The TFP growth differentials across sectors are small; the largest difference is about 0.5 percent per year between manufacturing and services. As a result, despite the Leontief preferences, sector-biased productivity growth alone (without trade and non-homothetic preferences) plays a small role in explaining Korea's structural change.
} 


\section{Conclusion}

Our main contribution is a quantitative assessment of the role of international trade in structural change. We employ a three-sector, two-country model with non-unitary income and substitution elasticities, and intermediate goods, and with sector-biased, time-varying productivity and trade cost shocks. We calibrate our framework to investigate South Korea's structural change between 1971 and 2005. The benchmark model accounts for virtually the entire evolution of labor shares in agriculture and services, as well as the rising part of the hump-shape in manufacturing. The root mean square error of the closed economy version of the model is 60 percent higher than that of the benchmark model. Clearly, openness plays an indispensable role in Korea's structural change.

Moreover, counterfactual exercises that turn off either shock lead to a significant deterioration in the model performance. Trade cost shocks are important for agriculture and manufacturing, while productivity shocks are important for all three sectors — with these shocks exerting a stronger effect in the open economy, partly by changing patterns of specialization and partly by changing income. We also find that non-homothetic preferences are important for the evolution of services and agriculture.

While our calibrated model can quantitatively explain the rising portion of Korea's humpshape in manufacturing, it does not explain the declining portion of the hump. In this context, three useful extensions worth investigating include allowing for tradable services, endogenous trade imbalances, and a more general specification of preferences ${ }^{37}$ However, in our view, the key missing ingredient from the calibrated model is China. Over the past twenty years, China has opened up to international trade and trade volumes have surged. In 1991, Korea's and China's exports to the world were about the same, about 72 billion dollars. Over the next 14 years, China's exports grew by more than an order of magnitude to about 750 billion dollars, while Korea's grew only four-fold. China experienced manufacturing

\footnotetext{
${ }^{37}$ Kim and Kim (2003) show that even by 1998, services trade was about 20 percent of Korea's merchandise trade. Swiecki (2012) and Reyes-Heroles (2012) allow for trade imbalances, and Swiecki (2012) employs a more general preference structure than what we employ.
} 
productivity growth and lower trade costs that enabled it to essentially take market share in manufacturing from Korea. Thus, including China as a third country would help explain the declining portion of Korea's hump ${ }^{38}$ However, as discussed earlier, for China, good data do not exist before 1980, and in some cases, prior to 1990. Finding a way to include China is an exercise that we leave for future work.

\section{References}

[1] Acemoglu, Daron, and Veronica Guerrieri. 2008. "Capital Deepening and Nonbalanced Economic Growth." Journal of Political Economy, 116, 467-498.

[2] Autor, David H., David Dorn, and Gordon H. Hanson. 2011. "The China Syndrome: Local Labor Market Effects of Import Competition in the United States." Manuscript, MIT.

[3] Baumol, William J. 1967. "Macroeconomics of Unbalanced Growth: The Anatomy of Urban Crisis." American Economic Review, 57 (3), 415-426.

[4] Betts, Caroline, Rahul Giri, and Rubina Verma. 2011. "Trade, Reform, and Structural Transformation in South Korea" Manuscript, University of Southern California and ITAM.

[5] Buera, Francisco J. and Joseph P. Kaboski. 2009. "Can Traditional Theories of Structural Change Fit the Data?" Journal of the European Economic Association, 7, 469-477.

[6] Buera, Francisco J. and Joseph P. Kaboski. 2012. "Scale and the Origins of Structural Change" Journal of Economic Theory, 147, 684-712.

[7] Caliendo, Lorenzo and Fernando Parro. 2011. "Estimates of the Trade and Welfare Effects of NAFTA" Manuscript, Yale University and Federal Reserve Board.

[8] Caselli, Francesco and Wilbur John Coleman II. 2001. "The U.S. Structural Transformation and Regional Convergence: A Reinterpretation." Journal of Political Economy, 109, 584-616.

[9] Coleman, Wilbur John II. 2007. "Accommodating Emerging Giants" Manuscript, Duke University.

[10] Deardorff, Alan V. 2004. "Local Comparative Advantage: Trade Costs and the Pattern of Trade." Discussion Paper No. 500, University of Michigan.

\footnotetext{
${ }^{38}$ Our calibration also does not include Southeast Asian countries like Singapore, Taiwan, Malaysia, Thailand, and Indonesia. Adding these countries would also help explain the declining share of the hump.
} 
[11] Desmet, Klaus and Esteban Rossi-Hansberg. 2009. "Spatial Development" Manuscript, Universidad Carlos III and Princeton University.

[12] di Giovanni, Julian, Andrei A. Levchenko, and Jing Zhang. 2012. "The Global Welfare Impact of China: Trade Integration and Technological Change." Mimeo, University of Michigan.

[13] Duarte, Margarida and Diego Restuccia. 2010. "The Role of the Structural Transformation in Aggregate Productivity" Quarterly Journal of Economics, 125, 129-173.

[14] Eaton, Jonathan, and Samuel Kortum. 2002. "Technology, Geography, and Trade." Econometrica, 70, 1741-1779.

[15] Echevarria, Cristina. 1995. "Agricultural Development vs. Industrialization: Effects of Trade." Canadian Journal of Economics, 28, 631-647.

[16] Echevarria, Cristina. 1997. "Changes in Sectoral Composition Associated with Economic Growth "International Economic Review, 38, 431-452.

[17] Finicelli, Andrea, Patrizio Pagano, and Massimo Sbracia. 2012. "Ricardian Selection" Journal of International Economics, 89, 96-109.

[18] Foellmi, Reto, and Josef Zweimuller. 2008. "Structural Change, Engel's Consumption Cycles, and Kaldor's Facts of Economic Growth" Journal of Monetary Economics, 55, 1317-1328.

[19] Galor, Oded, and Andrew Mountford. 2008. "Trading Population for Productivity: Theory and Evidence." Review of Economic Studies, 75, 1143-1179.

[20] Herrendorf, Berthold, Richard Rogerson, and Akos Valentinyi. 2012. "Two Perspectives on Preferences and Structural Transformation." Manuscript.

[21] Ju, Jiandong, Justin Yifu Lin, and Yong Wang. 2009. "Endowment Structures, Industrial Dynamics, and Economic Growth." Manuscript, IMF and University of Oklahoma.

[22] Kim, Jong-Il, and June-Dong Kim. 2003. "Liberalization of Trade in Services and Productivity Growth in Korea." Trade in Services in the Asia Pacific Region, NBER East Asia Seminar on Economics, Volume 11 Eds. Takatoshi Ito and Anne O. Krueger. University of Chicago Press.

[23] Kongsamut, Piyabha, Sergio Rebelo and Danyang Xie. 2001. "Beyond Balanced Growth." Review of Economic Studies, 68, 869-882.

[24] Laitner, John. 2000. "Structural Change and Economic Growth." Review of Economic Studies, 67, 545-561.

[25] Levchenko, Andrei A., and Jing Zhang. 2012. "The Evolution of Comparative Advantage: Measurement and Welfare Implications." NBER Working Paper No. 16806. 
[26] Maddison, Angus. 1991. Dynamic Forces in Capitalist Development: A Long-Run Comparative View, Oxford: Oxford University Press.

[27] Matsuyama, Kiminori. 1992. "Agricultural Productivity, Comparative Advantage and Economic Growth." Journal of Economic Theory, 58, 317-334.

[28] Matsuyama, Kiminori. 2009. "Structural Change in an Interdependent World: A Global View of Manufacturing Decline." Journal of the European Economic Association, 7, 478486.

[29] Ngai, Rachel L., and Christopher A. Pissarides. 2007. "Structural Change in a Multisector Model of Growth." American Economic Review, 97, 429-443.

[30] Restuccia, Diego, Dennis Tao Yang, and Xiaodong Zhu. 2008. "Agriculture and Aggregate Productivity: A Quantitative Cross-Country Analysis." Journal of Monetary Economics, 55, 234-250.

[31] Reyes-Heroles, Ricardo. 2012. "Structural Change in an Open Economy: A Quantitative Exploration." Manuscript, Princeton University.

[32] Rogerson, Richard. 2008. "Structural Transformation and the Deterioration of European Labor Market Outcomes." Journal of Political Economy, 116, 235-259.

[33] Shikher, Serge. 2012. "Predicting the Effects of NAFTA: Now We Can Do it Better!" Journal of International and Global Economic Studies, 5, 32-59.

[34] Simonovska, Ina, and Michael Waugh. 2011. "Different Trade Models, Different Trade Elasticities?" NBER Working Paper No. 16796.

[35] Sposi, Michael. 2012. "Evolving Comparative Advantage, Structural Change and the Composition of Trade." Manuscript, University of Iowa.

[36] Stefanski, Radoslaw. 2012. "Structural Transformation and the Oil Price." Manuscript, Oxford University.

[37] Swiecki, Tomasz. 2012. "Intersectoral Distortions, Structural Change, and the Welfare Gains from Trade." Manuscript, Princeton University.

[38] Teignier-Bacque, Marc. 2012. "The Role of Trade in Structural Transformation." Manuscript, Universidad de Alicante.

[39] Timmer, Marcel P. and Gaaitzen J. de Vries. 2007. "A Cross-Country Database for Sectoral Employment and Productivity in Asia and Latin America, 1950-2005." Groningen Growth and Development Centre Research Memorandum GD-98, Groningen: University of Groningen.

[40] Ungor, Murat. 2012. "De-industrialization of the Riches and the Rise of China." Manuscript, Central Bank of Turkey. 
[41] Verma, Rubina. 2012. "Can Total Factor Productivity Explain Value Added Growth in Services?" Journal of Development Economics, 99, 163-177.

[42] Waugh, Michael. 2010. "International Trade and Income Differences." American Economic Review, 100 (5), 2093-2124. 
Table 1: Parameter Values and Calibration Targets

\begin{tabular}{|c|c|c|c|c|c|c|c|}
\hline \multicolumn{8}{|c|}{ Preference Parameters } \\
\hline$\epsilon$ & & $\omega_{m}$ & $\omega_{s}$ & $\bar{C}_{a}$ & $\bar{C}_{m}$ & $\bar{C}_{s}$ & $\eta$ \\
\hline 0.751 & 0.131 & 0.214 & 0.655 & 696.0 & 0.0 & 0.0 & 4.0 \\
\hline \multicolumn{8}{|c|}{ Production Parameters } \\
\hline \multirow{2}{*}{\multicolumn{2}{|c|}{$\lambda_{j}$}} & \multicolumn{4}{|c|}{$\gamma_{\text {row }, \text { column }}$} & & \multirow[t]{2}{*}{$\theta$} \\
\hline & & & Agr & Man & Ser & & \\
\hline 0.456 & & Agr & 0.665 & 0.165 & 0.171 & & 4.0 \\
\hline 0.275 & & Man & 0.118 & 0.699 & 0.183 & & \\
\hline 0.576 & & Ser & 0.073 & 0.396 & 0.530 & & \\
\hline \multicolumn{8}{|c|}{ Initial Period Calibration Targets } \\
\hline & & & & & & Data & Model \\
\hline \multicolumn{6}{|c|}{ SK agricultural labor share } & 0.48 & 0.48 \\
\hline \multicolumn{6}{|c|}{ SK manufacturing labor share } & 0.13 & 0.13 \\
\hline \multicolumn{6}{|c|}{ SK agricultural subsistence share } & 0.51 & 0.54 \\
\hline \multicolumn{6}{|c|}{ ROW agricultural labor share } & 0.16 & 0.16 \\
\hline \multicolumn{6}{|c|}{ ROW manufacturing labor share } & 0.23 & 0.23 \\
\hline \multicolumn{6}{|c|}{ Income of ROW relative to SK } & 5.90 & 7.00 \\
\hline \multicolumn{6}{|c|}{ SK agricultural import share } & 0.12 & 0.04 \\
\hline \multicolumn{6}{|c|}{ SK manufacturing import share } & 0.26 & 0.26 \\
\hline \multicolumn{6}{|c|}{ SK agricultural export share } & 0.02 & 0.09 \\
\hline \multicolumn{6}{|c|}{ SK manufacturing export share } & 0.16 & 0.16 \\
\hline
\end{tabular}


Table 2: Model Performance: RMSE

\begin{tabular}{lcc}
\hline \hline & Non-homothetic & Homothetic \\
& Preferences & Preferences \\
Open economy & 0.053 & 0.122 \\
Closed economy & 0.083 & 0.175 \\
\hline \hline
\end{tabular}

Note: This table reports, for each model specification - e.g., non-homothetic preferences, open economy - the root mean squared error (RMSE) between the observed labor shares and the model-implied labor shares across all three sectors and the entire sample period. 
Figure 1: Korean Structural Change

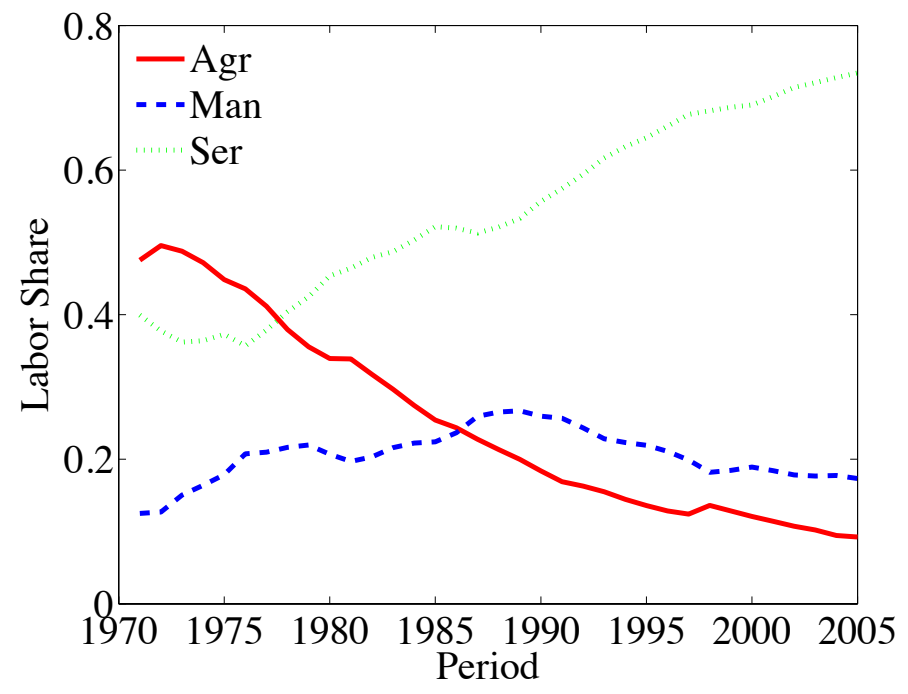


Figure 2: Calibrated TFP Series

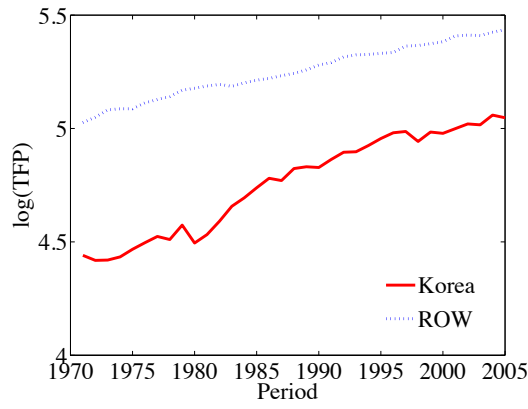

(a) Agriculture

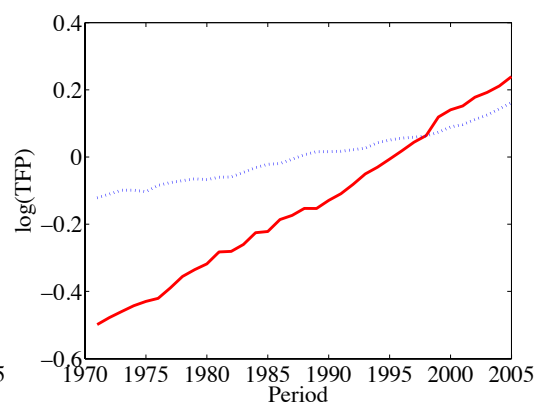

(b) Manufacturing

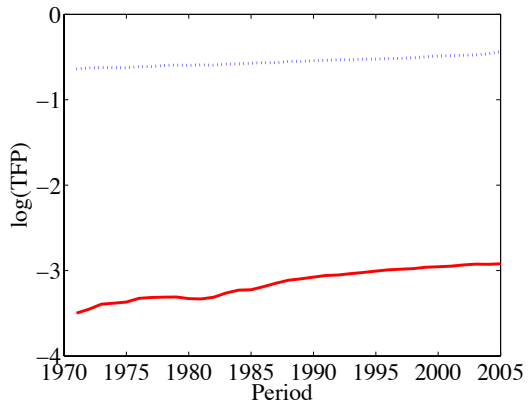

(c) Services 
Figure 3: Calibrated Trade Costs and Korean Trade Shares

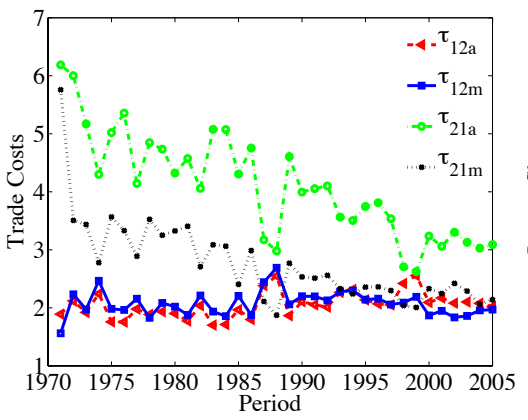

(a) Trade Costs

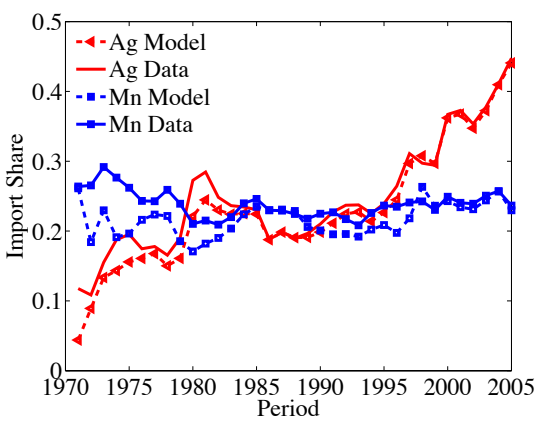

(b) Korean Import Shares

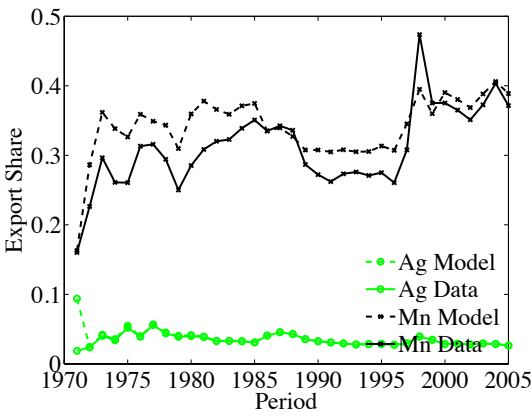

(c) Korean Export Shares 
Figure 4: Korean Structural Change: Benchmark

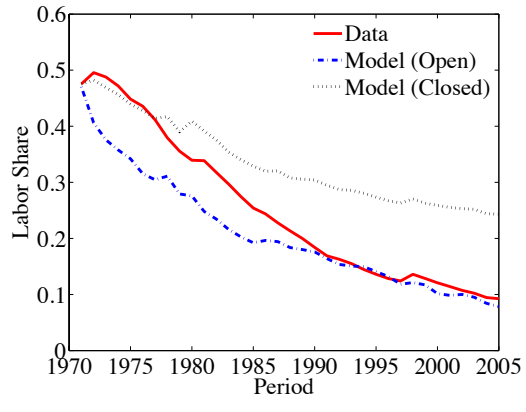

(a) Agriculture

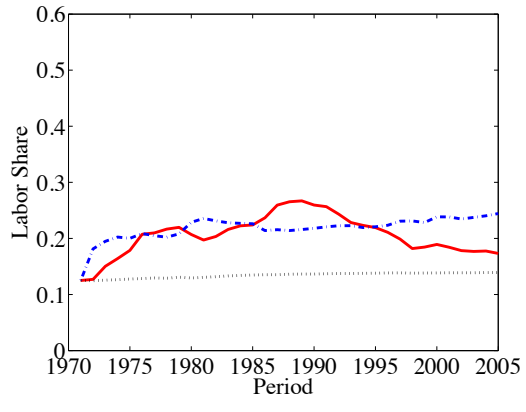

(b) Manufacturing

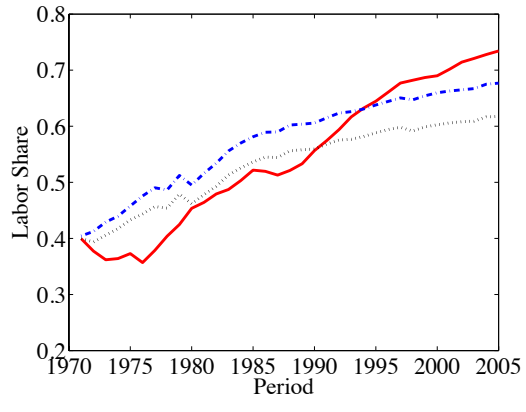

(c) Services 
Figure 5: Korean Output Shares: Benchmark

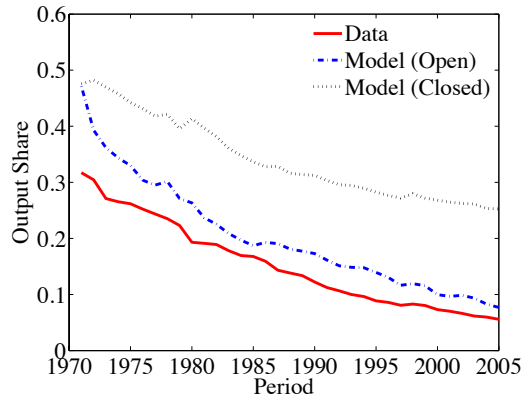

(a) Agriculture

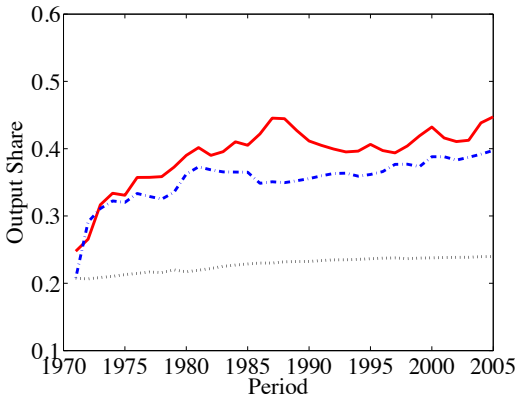

(b) Manufacturing

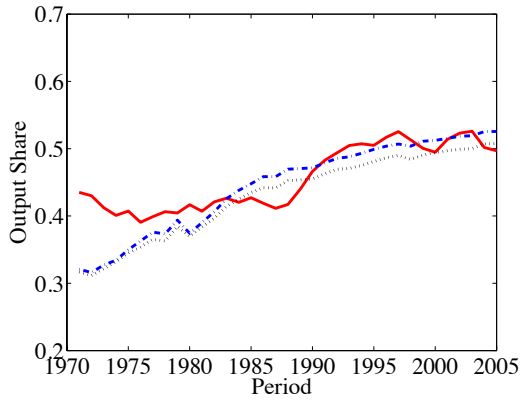

(c) Services 
Figure 6: Korean Structural Change: Constant TFPs

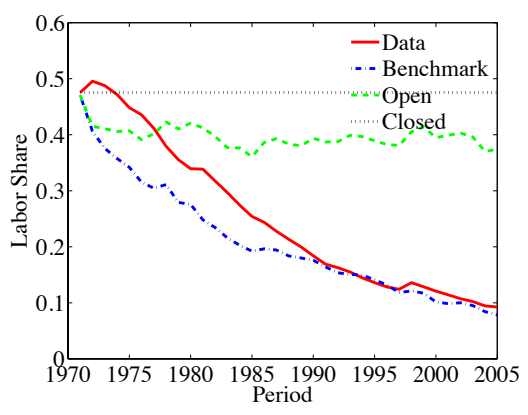

(a) Agriculture

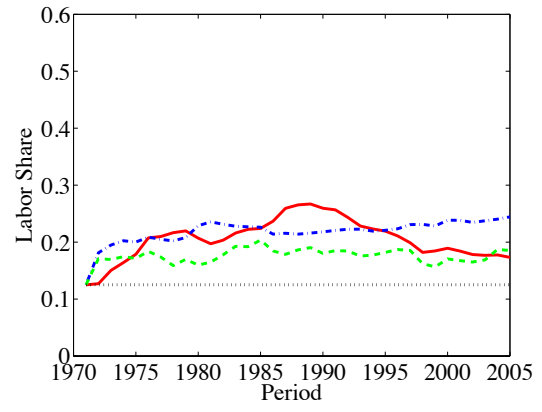

(b) Manufacturing

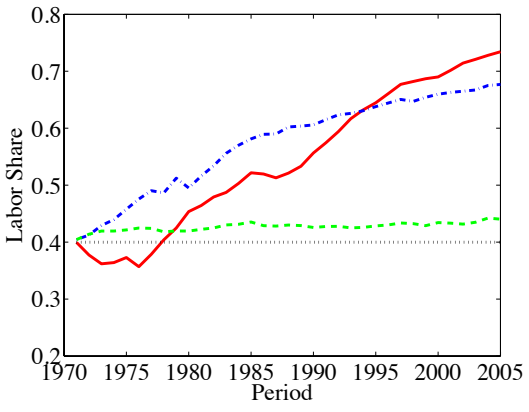

(c) Services 
Figure 7: Korean Structural Change: Constant Trade Costs

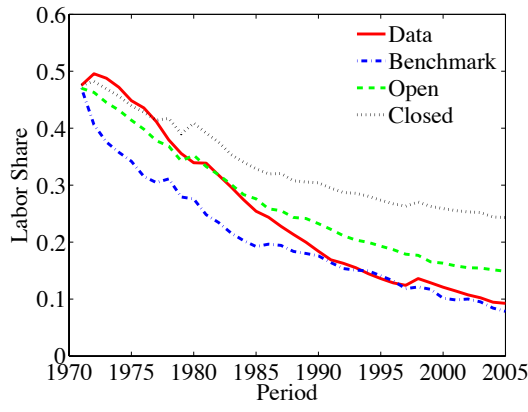

(a) Agriculture

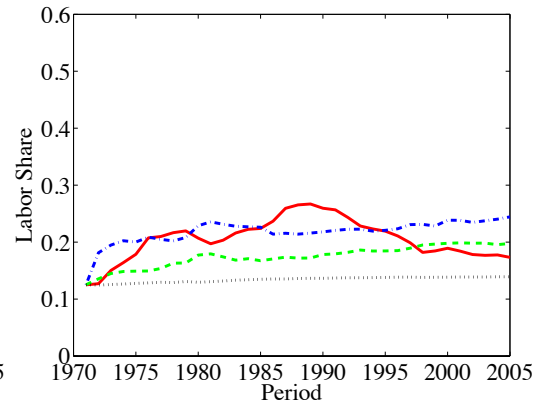

(b) Manufacturing

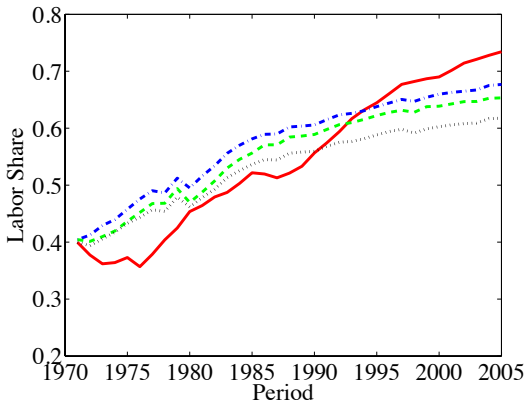

(c) Services 
Figure 8: Korean Structural Change: Homothetic Preferences

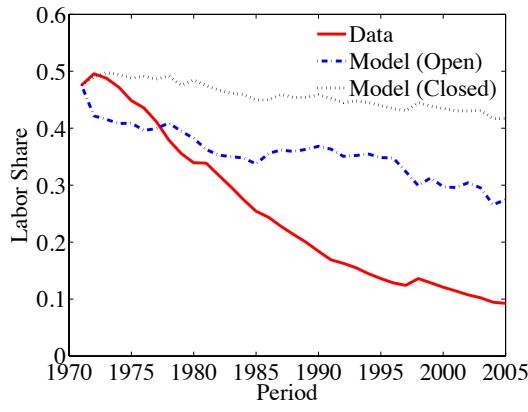

(a) Agriculture

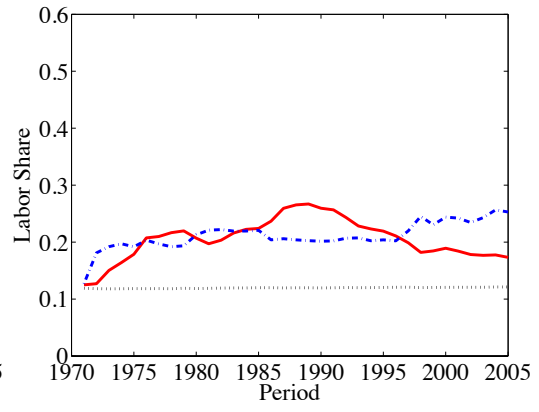

(b) Manufacturing

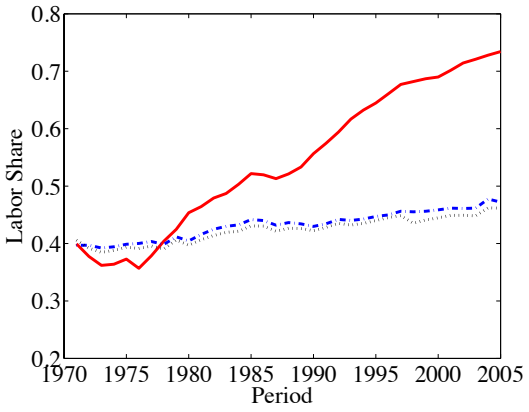

(c) Services 


\section{Appendix}

\subsection{Countries, Sample Period, and Sectors}

The 26 countries covered in our data set are Australia, Austria, Belgium, Canada, Denmark, Spain, Finland, France, Germany, Greece, Iran, Iraq, Ireland, Italy, Japan, South Korea, Kuwait, Luxembourg, Mexico, the Netherlands, Portugal, Saudi Arabia, Sweden, the United Kingdom, the United States, and Venezuela. All the countries but South Korea make up the rest of the world (ROW). Our data covers the period 1971-2005 39

Unless otherwise noted, the sectors are defined by the International Standard Industrial Classification, revision 3 (ISIC III) definitions: Agriculture corresponds to ISIC divisions 1-5 (agriculture, forestry, hunting, and fishing), 10-14 (mining and quarry), 15-16 (food, beverages and tobacco-FBT); Manufacturing corresponds to divisions 17-37 (total manufacturing less FBT); Services corresponds to divisions 40-99 (utilities, construction, wholesale and retail trade, transport, government, financial, professional, and personal services such as education, health care, and real estate services) ${ }^{40}$

\subsection{Sectoral Employment Shares}

Our sectoral employment data comes from two data sources, the EU KLEMS database, and the GGDC 10-sector database (Timmer and de Vries, 2007) ${ }^{41}$ The EU KLEMS database is the primary source for South Korea, the United States, Australia, Austria, Belgium, Canada, Denmark, Spain, Finland, France, Germany, Greece, Ireland, Italy, Japan, Luxembourg, the Netherlands, Portugal, Sweden, and the United Kingdom. We use the variable EMP, which measures the number of persons employed, and aggregate the data into three broader sectors.

The primary source for Mexico and Venezuela is the GGDC 10-sector database. For both countries, we use Table 3 (Number of Persons Employed) and aggregate the data into our three broad sectors. Since employment data for food, beverages and tobacco is not available in the 10-sector data, it remains part of the manufacturing sector for these two countries. For Iran, Iraq, Kuwait, and Saudi Arabia, we impute their sectoral employment under the assumption that their employment-population ratio and sectoral employment share are the same as in Venezuela (VEN). Using population data (POP) from Penn World Tables Version 7.0 (PWT) ${ }^{42}$ we compute total employment in each country $i$ as $L_{i}=\mathrm{POP}_{i} \times L_{\mathrm{VEN}} / \mathrm{POP}_{\mathrm{VEN}}$. Country $i$ 's employment in sector $k$ is given by $L_{i} \times l_{\mathrm{VEN}, k}$.

For each sector, the sectoral employment share $l_{i k}$ for country $i$ is defined as the ratio of sectoral employment $L_{i k}$ to total employment $L_{i}$. Total employment in a country is the sum across sectors of sectoral employment. We normalize total employment in each country by dividing by the U.S. population in 1971. ROW sectoral and total employment is

\footnotetext{
${ }^{39}$ For a few series, not all countries are included in the data due to limited availability.

${ }^{40}$ In a few cases, food, beverages and tobacco remains part of manufacturing due to limited data availability. Also, the data series on final consumption expenditure and the production parameters are not compatible with the ISIC III classification. See below for a detailed definition of sectors for these two variables.

${ }^{41}$ See http://www.euklems.net/ and http://www.rug.nl/feb/onderzoek/onderzoekscentra/ggdc/ data/10sector.

${ }^{42}$ http://pwt.econ.upenn.edu/php_site/pwt_index.php.
} 
the sum across all countries of each country's sectoral employment and total employment, respectively.

\subsection{South Korea's Trade Shares}

South Korea's sectoral import (export) shares are defined as sectoral imports (exports) divided by the difference between sectoral gross output and sectoral net export. Our primary source for trade flows is COMTRADE, which reports bilateral trade flows by commodity in U.S. dollars. When downloading from COMTRADE, we select South Korea (country code: 410) as the reporter and the world (country code: 0) as the partner. We define sectors based on the SITC Rev.1 classification as follows. In particular, we put FBT into the agriculture sector.

\begin{tabular}{l|l|l}
\hline \hline Agriculture & FBT & Manufacturing \\
\hline $00,011,023,024,025,031,041$, & $012,013,022,032,046,047$, & $251,26,332,4,5,6,7$, \\
$042,043,044,045,051,052,054$, & $048,053,055,06,081,091$, & 8 \\
$07,2,32,331,34,35$ & 099,1 & \\
\hline \hline
\end{tabular}

We obtain the nominal sectoral gross output series for South Korea using national accounts data from the Bank of Korea. ${ }^{43}$ The nominal exchange rate used to convert Korea's output in local currency to dollars is the variable "xrat" from the Penn World Tables version 7.0.

\subsection{Production Parameters}

We calibrate the production parameters $\left\{\lambda_{k}, \gamma_{k n}\right\}_{k, n=a, m, s}$ using South Korea's input-output tables provided by the Bank of Korea. The following table summarizes the available years and the aggregation of detailed sectors in the raw data into our three broad sectors.

\begin{tabular}{lccc}
\hline \hline Year & \multicolumn{3}{c}{ Sector Codes } \\
\cline { 2 - 4 } & Agriculture & Manufacturing & Services \\
\hline 1970 & $1-15$ & $16-41$ & $42-56$ \\
1975 & $1-16$ & $17-44$ & $45-60$ \\
1980 & $1-18$ & $19-45$ & $46-64$ \\
$1985-1988$ & $1-3$ & $4-11$ & $12-20$ \\
1990,1993 & $1-3$ & $4-15$ & $16-26$ \\
$1995,1998,2000,2003$ & $1-3$ & $4-16$ & $17-28$ \\
2005 & $1-3$ & $4-17$ & $18-28$ \\
\hline \hline
\end{tabular}

The parameter $\lambda_{k}$ is given by the share of value added in gross output in sector $k$. The $3 \times 3$ matrix $\left\{\gamma_{k n}\right\}$ is the use intensity of sector $n$ goods in producing sector $k$ goods, with $\sum_{n=a, m, s} \gamma_{k n}=1$. We calculate these parameters for every available input-output table and then take the sample mean. The values of the parameters are reported in Table 1.

\footnotetext{
${ }^{43}$ Table 10.4.5 Gross Value Added and Factor Income by Kind of Economic Activity (at current prices, annual). Available for download at http://ecos.bok.or.kr/
} 


\subsection{Sectoral TFP Growth}

We construct annual TFP growth for South Korea and the rest of the world for both the closed and open economy cases. The TFP concept in our model is a gross output concept. Owing to data limitations, however, we are unable to compute TFP directly from the gross output production function. Instead, we derive the value-added production function, which provides a mapping from value-added TFP to gross output TFP. We then show how to map from the measured TFP, which includes the effects of being in an open economy, to the fundamental TFP in each country and sector. Finally, we discuss how we implement computing value-added TFP and the open economy adjustment.

\section{Deriving valued-added TFP from gross output TFP}

Recall that goods are produced with labor and sectoral composite goods:

$$
Y_{i k}(z)=A_{i k}(z) L_{i k}(z)^{\lambda_{k}}\left[\Pi_{n=a, m, s} M_{i k n}^{\gamma_{k n}}(z)\right]^{1-\lambda_{k}} .
$$

Abstracting from the continuum of goods and working with sectoral aggregates gives

$$
\max _{L_{i k}, M_{i k n}} P_{i k} Y_{i k}-w_{i} L_{i k}-\sum_{n=a, m, s} P_{i n} M_{i k n}
$$

The first order condition gives the demand for intermediate goods

$$
M_{i k n}=\left(1-\lambda_{k}\right) \gamma_{k n} P_{i k} Y_{i k} / P_{i n}
$$

Substituting for $M_{i k n}$ in the production function and rearranging the terms gives

$$
Y_{i k}=\left[\left(1-\lambda_{k}\right) P_{i k} \Pi_{n=a, m, s}\left(\frac{\gamma_{k n}}{P_{i n}}\right)^{\gamma_{k n}}\right]^{\frac{1-\lambda_{k}}{\lambda_{k}}} A_{i k}^{\frac{1}{\lambda_{k}}} L_{i k}
$$

Thus, we can rewrite the maximization problem only in terms of choosing labor:

$$
\max _{L_{i k}} \quad \lambda_{k} P_{i k}^{\frac{1}{\lambda_{k}}}\left[\left(1-\lambda_{k}\right) \Pi_{n=a, m, s}\left(\frac{\gamma_{k n}}{P_{i n}}\right)^{\gamma_{k n}}\right]^{\frac{1-\lambda_{k}}{\lambda_{k}}} A_{i k}^{\frac{1}{\lambda_{k}}} L_{i k}-w_{i} L_{i k}
$$

The value added production function has the form $A_{i k}^{\frac{1}{\lambda_{k}}} L_{i k}$ with its corresponding price being $\lambda_{k} P_{i k}^{\frac{1}{\lambda_{k}}}\left[\left(1-\lambda_{k}\right) \Pi_{n=a, m, s}\left(\frac{\gamma_{k n}}{P_{i n}}\right)^{\gamma_{k n}}\right]^{\frac{1-\lambda_{k}}{\lambda_{k}}}$.

\section{Adjusting TFP for an Open Economy Setting}

As a reminder, the measured TFP in an open economy setting captures the effects of both specialization and the fundamental TFP, i.e., the TFP that would exist under autarky. To recover the fundamental TFP from the measured TFP, we follow Finicelli, Pagano, and Sbracia (FPS, 2012). Recall that in our model, each country $i$ possesses the technology to produce all goods in each sector. The productivity $A_{i k}(z)$ is the realization of random variable $Z_{i k}$, drawn from Fréchet distribution $F_{i k}\left(T_{i k}, \theta\right)$. Fundamental TFP is the unconditional 
mean of $Z_{i k}$, given by

$$
A_{i k}=E\left[Z_{i k}\right]=T_{i k}^{1 / \theta} \Gamma\left(\frac{\theta-1}{\theta}\right) .
$$

We denote the measured TFP for tradable sector $k$ in an open economy setting by $\tilde{A}_{i k}$, the average productivity conditional on the good being produced by country $i$. Proposition 5 of FPS shows that trade shares serve as a link between fundamental TFP and measured TFP in an open economy setting. Specifically,

$$
A_{i k}=\pi_{i i k}^{1 / \theta} \tilde{A}_{i k}
$$

$\pi_{i i k}$ is the sectoral domestic absorption ratio. Autarky, where $\pi_{i i k}=1$, is a special case in which the fundamental TFP and measured TFP coincide.

\section{Computing Sectoral Value Added}

The relation between value added labor productivity and gross output TFP allows us to measure gross output TFP using real value added (RVA) and employment data:

$$
A_{i k t}=\left(\frac{\mathrm{RVA}_{i k t}}{L_{i k t}}\right)^{\lambda_{k}}
$$

The two main ingredients for constructing TFP growth are sectoral employment and sectoral real value added for both South Korea and the ROW. The construction of sectoral employment series has been discussed above. We now focus on sectoral real value-added in 2000 U.S. dollars, which is constructed in three major steps. We combine the disaggregated real value added data into our three broad sectors. As we will discuss in detail next, this procedure differs across countries, because different countries and databases adopt different measures of real value added. In particular, South Korea uses Laspeyres indexes, the U.S. uses the Fischer method, whereas EU KLEMS uses Tornqvist indexes. We also use an appropriate PPP exchange rate to convert real value added in the national currency to U.S. dollars. Finally, we aggregate sectoral real value added across countries for the ROW.

South Korea Our primary source is GDP by kind of economic activity at current prices and at chained 2005 prices from the Bank of Korea.44 Both series are measured in billions of won. The real series is aggregated using Laspeyres price indices, with a base year of 2005 . First, we aggregate the real value added from the detailed industries into our three broad sectors. In particular, suppressing indices for countries, we use $\mathrm{VA}_{x k t}$ to denote nominal value added of a subsector $x$ within one of the three broad sectors $k \in\{a, m, s\}$ at time $t$, $\mathrm{VA}_{x k t}^{2005}$ and $\mathrm{VA}_{x k t}^{2000}$ denote real value added of the same subsector at chained 2005 and 2000 prices, respectively. Because we choose 2000 to be the base year, the following holds:

$$
\mathrm{VA}_{k 2000}^{2000}=\sum_{x \in X_{k}} \mathrm{VA}_{x k 2000},
$$

\footnotetext{
${ }^{44}$ The data is available for download from the Bank of Korea ecos.bok.or. $\mathrm{kr} / 10$.National Accounts/10.4 Supporting Tables/10.4.1.3 GDP and GNI by Kind of Economic Activity (at current prices, quarterly \& annual) and 10.4.1.4 GDP and GNI by Kind of Economic Activity (at chained 2005 year prices, quarterly \& annual).
} 
where $X_{k}$ is the set of subsectors within sector $k 4^{45}$ Using Laspeyres indices, the growth rate of sectoral value added at chained 2000 prices is given by

$$
\frac{\mathrm{VA}_{k t}^{2000}}{\mathrm{VA}_{k t+1}^{2000}}=\frac{\sum_{x \in X_{k}} \mathrm{VA}_{x k t}}{\sum_{x \in X_{k}} \mathrm{VA}_{x k t+1}^{2005}\left(\frac{\mathrm{VA}_{x k t}}{\mathrm{VA}_{x k t}^{2005}}\right)}
$$

For years prior to 2000, we iterate backwards, and for years after 2000, we iterate forwards.

We then convert sectoral real value added from Korean won to 2000 U.S. dollars. To do that, we need to impute the PPP for value added for each sector. We begin by assuming that the PPP for each sector is 788.92 in 2005, which is from the OECD PPP 2005 Benchmark results. 46 The PPP for sector $k$ at year 2000 is given by

$$
\mathrm{PPP}_{k 2000}=\mathrm{PPP}_{k 2005}\left(\frac{\mathrm{VA}_{\mathrm{SK} k 2005}^{2000}}{\mathrm{VA}_{\mathrm{SK} k 2005}}\right)\left(\frac{\mathrm{VA}_{\mathrm{US} k 2005}}{\mathrm{VA}_{\mathrm{US} k 2005}^{2000}}\right) .
$$

Finally, sectoral real value added for South Korea per worker is calculated as

$$
\mathrm{RVA}_{\mathrm{SK} k t}^{2000 \mathrm{USD}}=\frac{\mathrm{VA}_{\mathrm{SKkt}}^{2000} / \mathrm{PPP}_{k 2000}}{L_{\mathrm{SK} k t}} .
$$

United States The procedure for constructing sectoral real value added for the U.S. is similar to that of South Korea. Because national accounts data from the BEA are our primary sources for the U.S., we need to aggregate sectoral real value added using Fischer indexes ${ }^{47}$ First, we compute relative price $\mathrm{IPD}_{x k t}=\frac{\mathrm{VA}_{x k t}}{\mathrm{VA}_{x k t}^{2005}}$, for all subsectors $x \in X_{k}$ within sector $k \in\{a, m, s\}$. Next, we calculate Fischer Indexes (FI) for each sector $k$ at year $t$, which is given by:

$$
\mathrm{FI}_{k t}=\sqrt{\frac{\mathrm{VA}_{k t}}{\sum_{x \in X_{k}} \mathrm{IPD}_{x k t} \mathrm{VA}_{x k t-1}^{2005}} \times \frac{\mathrm{VA}_{k t-1}}{\sum_{x \in X_{k}} \mathrm{IPD}_{x k t-1} \mathrm{VA}_{x k t}^{2005}}} .
$$

By setting the sectoral chained indexes to be 100 in the year 2000, we can solve for the sectoral chained indices (CI) for other years using the equation

$$
\frac{\mathrm{CI}_{k t}}{\mathrm{CI}_{k t+1}}=\frac{1}{\mathrm{FI}_{k t+1}} \text {. }
$$

\footnotetext{
${ }^{45}$ The aggregation here is standard, following the ISIC rev. 3 definition of sectors, and FBT is included in agriculture.

${ }^{46}$ This number is obtained from OECD Purchasing Power Parities (PPP) 2005 Benchmark results. The dataset can be accessed at http://stats.oecd.org/Index.aspx?DatasetCode=STAN08BIS\#, Table 1.12: Purchasing Power Parities in national currencies per US dollar. The corresponding PWT v7.0 PPP number is virtually identical.

${ }^{47}$ We obtained a comprehensive table on nominal and real value added by industry from the BEA. We use the following two variables from the table, nominal value-added by industry (1947-2009), and Chained Price Indexes (2005=100, 1947-2009).
} 
In the end, we compute sectoral value added at chained 2000 prices using

$$
\mathrm{VA}_{k t}^{2000}=\mathrm{VA}_{k 2000} \mathrm{CI}_{k 2000} / 100 \text {. }
$$

Because of data limitations, we need to impute real FBT value-added for the U.S. prior to 1977. Specifically, we make use of nominal FBT value added and the corresponding chained quantity indexes (QI) to compute a real FBT share ${ }^{48}$ We then assume that the real FBT share stays constant at the 1977 level from 1971-1977. The real FBT share in 1977 is given by

$$
\frac{\mathrm{VA}_{\mathrm{FBT} 2000} * \mathrm{QI}_{\mathrm{FBT} 1977} / \mathrm{QI}_{\mathrm{FBT} 2000}}{\mathrm{VA}_{m 2000} * \mathrm{QI}_{m 1977} / \mathrm{QI}_{m 2000}} .
$$

We calculate real FBT value added by multiplying the share by real value added in manufacturing, and we use the result to make the appropriate adjustment to real value added in agriculture and in manufacturing for the relevant years.

The Rest of the World We need the sum of sectoral real value added and employment across all countries, including the U.S., to calculate real value added per worker for the ROW. Aggregating employment is straight-forward. For sectoral real value added, the EU KLEMS database is the primary source for Australia, Austria, Belgium, Canada, Denmark, Spain, Finland, France, Germany, Greece, Ireland, Italy, Japan, Luxembourg, the Netherlands, Portugal, Sweden, and the United Kingdom. For each country, we first convert nominal series in the national currency to current U.S. dollars using the PPPs from PWT 7.0. The underlying assumption is that within each country, PPPs for all industries are the same as the national PPP for every year. Second, we aggregate sectoral quantity indices (QI), (from EU KLEMS and with a base year of 1995), following the Tornqvist formula. The final step is to iteratively compute the annual series of real sectoral value added from nominal values in year 2000, using the implied growth rate from sectoral QI. The last two steps are described in detail below. For each individual country, we calculate the following:

1. The subsector weight is $\alpha_{x k t}=\frac{\mathrm{VA}_{x k t}+\mathrm{VA}_{x k t+1}}{\sum_{x \in X_{k}} \mathrm{VA}_{x k t}+\mathrm{VA}_{x k t+1}}$ for each subsector $x \in X_{k}$.

2. The subsector quantity index (QI) growth rate is $\log \left(\frac{\mathrm{QI}_{x t+1}}{\mathrm{QI}_{x t}}\right)$ for each subsector $x$.

3. The sector QI growth rate is $\Delta \mathrm{QI}_{k t}=\sum_{x \in X_{k}} \alpha_{x k t} \log \left(\frac{\mathrm{QI}_{x t+1}}{\mathrm{QI}_{x t}}\right)$ for each sector $k$.

4. For each sector $k, \mathrm{QI}_{k 1995}=100$, and $\mathrm{QI}_{k t}$ can be solved successively using $\log \mathrm{QI}_{k t}=$ $\log \mathrm{QI}_{k t-1}+\Delta \mathrm{QI}_{k t-1}$.

5. Real sectoral value added at constant $2000 \mathrm{USD}$ : set $\mathrm{VA}_{k t}^{2000 \mathrm{USD}}=\mathrm{VA}_{k 2000}$. Using the growth rate of sectoral value added implied by the quantity indices, we can iterate forward and backward to solve for sectoral value added in 2000 U.S. dollars for every year. In particular,

$$
\frac{\mathrm{VA}_{k t}^{2000 \mathrm{USD}}}{\mathrm{VA}_{k t+1}^{2000 \mathrm{USD}}}=\frac{\mathrm{QI}_{k t}}{\mathrm{QI}_{k t+1}} .
$$

${ }^{48}$ We obtain these two series from table "1947-97 GDPbyInd_VA_NAICS.xls" at http://www.bea.gov/ industry/gdpbyind_data.htm. 
The UN National Accounts Main Aggregates Database is the primary source for the oil countries, including Iran, Iraq, Kuwait, Mexico, Saudi Arabia, and Venezuela.49 Sectoral value added is reported in both current and constant 2005 U.S. dollars. Hence, we only need to renormalize the real series to constant 2000 U.S. dollars, given by $\mathrm{VA}_{k t}^{2000}=\mathrm{VA}_{k t}^{2005} \frac{\mathrm{VA}_{k 2000}}{\mathrm{VA}_{k 2000}^{2055}}{ }^{50}$

The final step is to sum up sectoral real value added in 2000 U.S. dollars and sectoral employment across countries in the ROW. Sectoral real value added per worker for the ROW is the ratio of these two terms.

\section{Computing TFP in an Open Economy}

Recall from above that the fundamental TFP in an open economy setting can be computed from observed TFPs by using the domestic absorption ratio $\pi_{i i k}$. We now discuss how we construct $\pi_{i i k}$ for South Korea and the rest of the world. For South Korea, we compute the ratio using the same trade flows and gross output data series discussed in above. For the ROW, we obtain the combined trade flows between South Korea and the countries in our ROW aggregate from COMTRADE, following the same classification of sectors as for South Korea's trade shares. In particular, we choose our subset of countries as reporters and South Korea as the partner country.

For gross output, the BEA industry accounts are the source for the U.S., supplemented by World Klems for 1971-1976 ${ }^{51}$ The EU KLEMS database is the primary source for Australia, Austria, Belgium, Canada, Denmark, Spain, Finland, France, Germany, Greece, Ireland, Italy, Japan, Luxembourg, the Netherlands, Portugal, Sweden, and the United Kingdom 52 For the oil countries, OECD STAN is the primary source for Mexico53 The Venezuela national accounts is the primary source for Venezuela. ${ }^{44}$ The UN National Accounts database is the source for Kuwait ${ }_{55}^{5}$ For Iran, Iraq, Saudi Arabia, we impute their sectoral gross output by multiplying sectoral gross output in Venezuela with the population ratio between these countries and Venezuela.

If the above data are in the national currency, we convert it into U.S. dollars using nominal exchange rates from PWT 7.0. We then aggregate nominal gross output of the detailed industries into our three broad sectors according to the ISIC III definition of sectors discussed above ${ }^{56}$ Finally, we compute the sectoral absorption ratio for the ROW from the combined import flows, export flows, and gross output of all countries in our sample.

\footnotetext{
${ }^{49}$ The data is available for download at http://unstats.un.org/unsd/snaama/selbasicFast.asp. We use both "Value Added by Economic Activity, at current prices - US dollars" and "Value Added by Economic Activity, at constant 2005 prices - US dollars."

${ }^{50}$ Since we do not have nominal or real FBT value added for oil countries, no FBT adjustment is made and it remains part of manufacturing for these countries.

${ }^{51}$ http://www.bea.gov/industry/gdpbyind_data.htm and http://www.worldklems.net/data/ index.htm.

${ }^{52}$ http://www. euklems.net//,

53 http://stats. oecd.org/Index.aspx?DatasetCode=STAN08BIS

${ }^{54}$ http://www.bcv.org.ve/cuadros/series/series.asp.

55 http://unstats.un.org/unsd/snaama/selbasicFast.asp.

${ }^{56}$ Gross output for FBT is not available for Kuwait and Venezuela and therefore it remains part of manufacturing. The sectoral aggregation for Venezuela is broadly consistent with the ISIC III definition, with the exception that manufacturing corresponds to "Industry" on the National Accounts table, which also includes refinement of petroleum.
} 


\subsection{Preference Parameters}

We now discuss the construction of time-series data for Korean aggregate consumption expenditure $\left\{P_{t} C_{t}\right\}$, sectoral consumption expenditure shares $\left\{s_{k t}\right\}$ and sectoral prices $\left\{P_{k t}\right\}$ that are used to estimate the preference parameters $\left\{\epsilon, \omega_{a}, \omega_{m}, \omega_{s}, \bar{C}_{a}, \bar{C}_{s}\right\}$.

The OECD national accounts database is the primary source for final consumption expenditures data. 57 The data are available in both current prices and 2000 prices, denominated in national currencies. We first aggregate both these series into our three broad sectors. The definition of the three broad sectors for final consumption expenditure follows the Classification of Individual Consumption According to Purpose (COICOP). Agriculture corresponds to P31CP010 (Food and non-alcoholic beverages) and P31CP020 (Alcoholic beverages, tobacco and narcotics). Manufacturing is the sum of P311B (Durable goods), P312B (Semi-durable goods), and P313B (Non-Durable goods), less agriculture. Services is given by P314B (Services).

The above aggregation procedure yields time-series for sectoral consumption expenditure in both current and 2000 prices (local currency units), denoted by $\left\{\hat{C}_{k t}, \hat{c}_{k t}\right\}_{k=a, m, s}$. Then, we compute the sectoral consumption share $s_{k t}$ as

$$
s_{k t}=\frac{\hat{C}_{k t}}{\sum_{k=a, m, s} \hat{C}_{k t}} .
$$

We then compute aggregate consumption expenditure per capita in current U.S. dollars $\left\{C_{t}\right\}$ by dividing nominal total consumption expenditure by population and the PPP for private consumption 58

$$
P_{t} C_{t}=\frac{\sum_{k=a, m, s} \hat{C}_{k t}}{\mathrm{POP}_{t} \mathrm{PPP}_{t}} .
$$

Finally, to compute sectoral relative prices $P_{k t}$ in U.S. dollars, we make the appropriate PPP adjustment to relative prices in terms of national currency:

$$
P_{k t}=\frac{\hat{C}_{k t}}{\mathrm{PPP}_{t}} / \frac{\hat{c}_{k t}}{\mathrm{PPP}_{2000}} .
$$

Armed with these time series, we proceed to minimize the squared distance between the model-implied consumption expenditure shares and their counterparts in the data, as described in the text. To this end, we first perform a grid search before using the estimates obtained with this method as the initial guess for a minimization routine that employs a quasi-newton method. The grid is constructed so as to ensure that model-implied sectoral consumption is positive. The final estimates obtained with the quasi-newton method do not differ greatly from the estimates using the grid search, though there is a slight improvement

\footnotetext{
${ }^{57}$ Table 5.Final consumption expenditure of households under Annual National Accounts/ Detailed Tables and Simplified Accounts. http://stats.oecd.org/Index.aspx?QueryId=9189.

${ }^{58}$ Table Population under "Demography and Population," http://stats.oecd.org/Index.aspx? QueryId=9189 Transaction "PPPPRC: Purchasing Power Parities for private consumption" in Table 4. PPPs and Exchange Rates, under "Prices and Purchasing Power Parities," http://stats.oecd.org/Index.aspx? QueryId=9189.
} 
in the overall loss. These are the estimates used to calibrate the preference parameters.

\section{Subsistence Share}

The subsistence share is used to calibrate the initial period parameters and exogenous variables in 1971. Recall that we calibrated the minimum per-capita consumption requirements in agriculture and services, $\bar{C}_{a}$ and $\bar{C}_{s}$, to be $\bar{C}_{a}=696.03$ and $\bar{C}_{s}=0$, (measured in 2000 U.S. dollars). We define the agriculture subsistence share as

$$
\frac{\text { Agr. relative price } \times \bar{C}_{a}}{\text { Total final consumption expenditure per capita }}=\frac{P_{a 1} \bar{C}_{a}}{P_{1} C_{1}},
$$

where $P_{a 1}$ and $C_{1}$ are the aforementioned relative price of agriculture and total consumption expenditure in the first period.

\section{$0.7 \quad$ Relative Income}

We compute the income per capita of the ROW relative to South Korea in 1971 as a calibration target for the initial period estimation in the open economy. Relative income is constructed using historical real GDP data from the International Macroeconomic Data Set. ${ }^{59}$ Both GDP and GDP per capita are reported in 2005 U.S. dollars for every country in our sample. For the ROW, we first compute population by dividing real GDP by real GDP per capita for each country. Using population as weights, we take a weighted average of real GDP per capita for the ROW. Our calculation yields a ratio of 5.9 between real GDP per capita of the ROW and South Korea in 1971.

\subsection{Conditions under which Manufacturing Productivity Growth Leads to a Hump Pattern}

Recall that in this scenario there are unit income and substitution elasticities of demand. (Preferences are homothetic and Cobb-Douglas across sectoral composite goods.) Assume that labor supply is constant in both countries. From the balanced-trade condition, the equilibrium wage ratio $w_{t}=\frac{w_{1 t}}{w_{2 t}}$ solves

$$
\left[\omega_{m} \pi_{21 m t}+\omega_{a} \pi_{21 a t}\right] \frac{w_{t} L_{1}+L_{2}}{w_{t} L_{1}}=\omega_{a}+\omega_{m}
$$

Totally differentiating equation (13), we have

$$
\frac{\omega_{m} \pi_{21 m t} \hat{\pi}_{21 m t}+\omega_{a} \pi_{21 a t} \hat{\pi}_{21 a t}}{\omega_{m} \pi_{21 m t}+\omega_{a} \pi_{21 a t}}-\frac{L_{2}}{w_{t} L_{1}+L_{2}} \hat{w}_{t}=0,
$$

\footnotetext{
${ }^{59}$ http://www .ers.usda.gov/data-products/international-macroeconomic-data-set.aspx.
} 
where $\hat{\pi}_{21 m t}=\theta \pi_{12 m t}\left(\hat{A}_{m}-\hat{w}_{t}\right)$ and $\hat{\pi}_{21 a t}=\theta \pi_{12 a t}\left(\hat{A}_{a}-\hat{w}_{t}\right)$. Solving for $\hat{w}_{t}$ yields

$$
\hat{w}_{t}=\frac{\psi_{m t} \hat{A}_{m}+\psi_{a t} \hat{A}_{a}}{\psi_{l t}+\psi_{m t}+\psi_{a t}}
$$

where $\psi_{l t}=\frac{L_{2}}{w_{t} L_{1}+L_{2}}, \psi_{m t}=\frac{\theta \omega_{m} \pi_{12 m t} \pi_{21 m t}}{\omega_{m} \pi_{21 m t}+\omega_{a} \pi_{21 a t}}$, and $\psi_{a t}=\frac{\theta \omega_{a} \pi_{12 a t} \pi_{21 a t}}{\omega_{m} \pi_{21 m t}+\omega_{a} \pi_{21 a t}}$. Since $\hat{A}_{a}$ and $\hat{A}_{m}$ are both positive, we have $\hat{w}_{t}$ is positive, which implies that the relative size of country 1 in the world economy keeps rising.

The manufacturing labor share in country 1 is given by $l_{1 m t}=\omega_{m} \pi_{21 m t}\left[\frac{w_{t} L_{1}+L_{2}}{w_{t} L_{1}}\right]$. Again totally differentiating, we have

$$
\hat{l}_{1 m t}=-\frac{L_{2}}{w_{t} L_{1}+L_{2}} \hat{w}_{t}+\hat{\pi}_{21 m t}=-\left[\frac{L_{2}}{w_{t} L_{1}+L_{2}}+\theta \pi_{12 m t}\right] \hat{w}_{t}+\theta \pi_{12 m t} \hat{A}_{m} .
$$

We then plug in the equation for $\hat{w}_{t}$ and simplify. The necessary and sufficient condition for $\hat{l}_{1 m t}>0$ is

$$
\hat{A}_{m}>\hat{A}_{a} \frac{L_{2} \pi_{12 a t}+\theta\left(w_{t} L_{1}+L_{2}\right) \pi_{12 a t} \pi_{12 m t}}{L_{2} \pi_{12 m t}+\theta\left(w_{t} L_{1}+L_{2}\right) \pi_{12 a t} \pi_{12 m t}} \equiv \hat{A}_{a} \xi_{t}
$$

where $\xi_{t}>1$, because $\pi_{12 a t}>\pi_{12 m t}$ under the pattern of comparative advantage.

Under the assumption that initially $\hat{A}_{m}$ and $\hat{A}_{a}$ satisfy equation $(14), \hat{l}_{1 m t}>0$, i.e., the manufacturing labor share in country 1 initially rises over time. It also implies that $\hat{A}_{m}>\hat{A}_{a}$ given that $\xi_{t}>1$. Moreover, $\hat{\pi}_{12 m t}=\theta \pi_{21 m t}\left(\hat{w}_{t}-\hat{A}_{m}\right)=-\frac{\theta \pi_{21 m t}\left(\hat{A}_{m} \phi_{l t}+\phi_{a t}\left(\hat{A}_{m}-\hat{A}_{a}\right)\right)}{\psi_{l t}+\psi_{m t}+\psi_{a t}}<0$. Thus, $\pi_{12 m t}$ declines over time to zero, or $\pi_{21 m t}$ rises over time to one.

When $\pi_{21 m t}$ approaches one over time, $l_{1 m t}$ starts to decline because $l_{1 m t}=\omega_{m} \pi_{21 m t}\left[\frac{w_{t} L_{1}+L_{2}}{w_{t} L_{1}}\right]$ and $\frac{w_{t} L_{1}+L_{2}}{w_{t} L_{1}}$ always declines over time. This completes the characterization of the hump pattern of $l_{1 m t}$. Q.E.D.

\subsection{Decomposition of Labor Shares into Net Export and Expen- diture Channels}

Now consider the open economy. Market clearing for country $i$ sector $q$ composite good is

$$
P_{i q} Q_{i q}=P_{i q} C_{i q}+\sum_{n=a, m}\left(1-\lambda_{n}\right) \gamma_{n q} \sum_{j=1,2} \pi_{j i n} P_{j n} Q_{j n}+\left(1-\lambda_{s}\right) \gamma_{s q} P_{i s} Q_{i s}
$$

where $Q_{i q}$ is the composite good, which is assumed to be non traded, and used in final consumption and as intermediates of all three sectors. Specializing this to South Korean agriculture, we obtain

$$
\begin{aligned}
& P_{1 a} Q_{1 a}=P_{1 a} C_{1 a}+\sum_{n=a, m}\left(1-\lambda_{n}\right) \gamma_{n a} \sum_{j=1,2} \pi_{j 1 n} P_{j n} Q_{j n}+\left(1-\lambda_{s}\right) \gamma_{s a} P_{1 s} Q_{1 s} \\
& P_{1 a} C_{1 a}=P_{1 a} Q_{1 a}-\sum_{n=a, m}\left(1-\lambda_{n}\right) \gamma_{n a} \sum_{j=1,2} \pi_{j 1 n} P_{j n} Q_{j n}-\left(1-\lambda_{s}\right) \gamma_{s a} P_{1 s} Q_{1 s}
\end{aligned}
$$


We next link $Q_{1 a}$ with $L_{1 a}$. We have

$$
\pi_{11 a} P_{1 a} Q_{1 a}+\pi_{12 a} P_{2 a} Q_{2 a}=\frac{w_{1} L_{1 a}}{\lambda_{a}} .
$$

Rewriting the above equation gives

$$
P_{1 a} Q_{1 a}-\pi_{12 a} P_{1 a} Q_{1 a}+\pi_{12 a} P_{2 a} Q_{2 a}=P_{1 a} Q_{1 a}+N X_{1 a}=\frac{w_{1} L_{1 a}}{\lambda_{a}} .
$$

Dividing both sides with $w_{1} L_{1}$ gives

$$
\frac{P_{1 a} Q_{1 a}}{w_{1} L_{1}}=\frac{1}{\lambda_{a}} l_{1 a}-N_{1 a}
$$

where $N_{1 a}$ denotes the ratio of agricultural net exports and GDP. Now expanding the inner double sum in Equation (17) and rearranging gives

$$
\begin{aligned}
P_{1 a} C_{1 a} & =P_{1 a} Q_{1 a}-\left(1-\lambda_{a}\right) \gamma_{a a}\left[\pi_{11 a} P_{1 a} Q_{1 a}+\pi_{21 a} P_{2 a} Q_{2 a}\right] \\
& -\left(1-\lambda_{m}\right) \gamma_{m a}\left[\pi_{11 m} P_{1 m} Q_{1 m}+\pi_{21 m} P_{2 m} Q_{2 m}\right]-\left(1-\lambda_{s}\right) \gamma_{s a} P_{1 s} Q_{1 s} \\
P_{1 a} C_{1 a} & =P_{1 a} Q_{1 a}-\left(1-\lambda_{a}\right) \gamma_{a a}\left[\left(1-\pi_{12 a}\right) P_{1 a} Q_{1 a}+\pi_{21 a} P_{2 a} Q_{2 a}\right] \\
& -\left(1-\lambda_{m}\right) \gamma_{m a}\left[\left(1-\pi_{12 m}\right) P_{1 m} Q_{1 m}+\pi_{21 m} P_{2 m} Q_{2 m}\right]-\left(1-\lambda_{s}\right) \gamma_{s a} P_{1 s} Q_{1 s} \\
P_{1 a} C_{1 a} & =P_{1 a} Q_{1 a}\left[1-\left(1-\lambda_{a}\right) \gamma_{a a}\right]-\left(1-\lambda_{a}\right) \gamma_{a a}\left[\pi_{21 a} P_{2 a} Q_{2 a}-\pi_{12 a} P_{1 a} Q_{1 a}\right] \\
& -P_{1 m} Q_{1 m}\left(1-\lambda_{m}\right) \gamma_{m a}-\left(1-\lambda_{m}\right) \gamma_{m a}\left[\pi_{21 m} P_{2 m} Q_{2 m}-\pi_{12 m} P_{1 m} Q_{1 m}\right]-P_{1 s} Q_{1 s}\left(1-\lambda_{s}\right) \gamma_{s a}
\end{aligned}
$$

We divide both sides of the above equation by $w_{1} L_{1}=P_{1} C_{1}$. Making use of equation (20) and the definitions of expenditure share and sectoral net exports shares, the last equation becomes

$$
\begin{aligned}
X_{1 a} & =\left[1-\left(1-\lambda_{a}\right) \gamma_{a a}\right]\left(\frac{1}{\lambda_{a}} l_{1 a}-N_{1 a}\right)-\left(1-\lambda_{a}\right) \gamma_{a a} N_{1 a}- \\
& -\left(1-\lambda_{m}\right) \gamma_{m a}\left(\frac{1}{\lambda_{m}} l_{1 m}-N_{1 m}\right)-\left(1-\lambda_{m}\right) \gamma_{m a} N_{1 m}-\left(1-\lambda_{s}\right) \gamma_{s a} \frac{1}{\lambda_{s}} l_{1 s} .
\end{aligned}
$$

Simplifying we get

$$
X_{1 a}+N_{1 a}=\frac{1-\left(1-\lambda_{a}\right) \gamma_{a a}}{\lambda_{a}} l_{1 a}-\frac{\left(1-\lambda_{m}\right) \gamma_{m a}}{\lambda_{m}} l_{1 m}-\frac{\left(1-\lambda_{s}\right) \gamma_{s a}}{\lambda_{s}} l_{1 s}
$$

We can write out the analogous expressions for the other two sectors in South Korea:

$$
\begin{aligned}
& X_{1 m}+N_{1 m}=\frac{1-\left(1-\lambda_{m}\right) \gamma_{m m}}{\lambda_{m}} l_{1 m}-\frac{\left(1-\lambda_{a}\right) \gamma_{a m}}{\lambda_{a}} l_{1 a}-\frac{\left(1-\lambda_{s}\right) \gamma_{s m}}{\lambda_{s}} l_{1 s} \\
& X_{1 s}=\frac{1-\left(1-\lambda_{s}\right) \gamma_{s s}}{\lambda_{s}} l_{1 s}-\frac{\left(1-\lambda_{m}\right) \gamma_{m s}}{\lambda_{m}} l_{1 m}-\frac{\left(1-\lambda_{a}\right) \gamma_{a s}}{\lambda_{a}} l_{1 a} .
\end{aligned}
$$


Collecting the last three equations, we can write out the relationship between the expenditure, net export and labor shares concisely in matrix form:

$$
I\left[\begin{array}{c}
X_{1 a} \\
X_{1 m} \\
X_{1 s}
\end{array}\right]+\Lambda\left[\begin{array}{c}
N_{1 a} \\
N_{1 m}
\end{array}\right]=\Omega\left[\begin{array}{c}
l_{1 a} \\
l_{1 m} \\
l_{1 s}
\end{array}\right],
$$

where the matrices I, $\Lambda$, and $\Omega$ are given by

$$
\begin{aligned}
& I=\left[\begin{array}{lll}
1 & 0 & 0 \\
0 & 1 & 0 \\
0 & 0 & 1
\end{array}\right], \quad \Lambda=\left[\begin{array}{ll}
1 & 0 \\
0 & 1 \\
0 & 0
\end{array}\right], \\
& \Omega=\left[\begin{array}{lll}
\frac{1-\gamma_{a a}\left(1-\lambda_{a}\right)}{\lambda_{a}} & -\frac{\gamma_{m a}\left(1-\lambda_{m}\right)}{\lambda_{m}} & -\frac{\gamma_{s a}\left(1-\lambda_{s}\right)}{\lambda_{s}} \\
-\frac{\gamma_{a m}\left(1-\lambda_{a}\right)}{\lambda_{a}} & \frac{1-\gamma_{m m}\left(1-\lambda_{m}\right)}{\lambda_{m}} & -\frac{\gamma_{s m}\left(1-\lambda_{s}\right)}{\lambda_{s}} \\
-\frac{\gamma_{a s}\left(1-\lambda_{a}\right)}{\lambda_{a}} & -\frac{\gamma_{m s}\left(1-\lambda_{m}\right)}{\lambda_{m}} & \frac{1-\gamma_{s s}\left(1-\lambda_{s}\right)}{\lambda_{s}}
\end{array}\right]
\end{aligned}
$$

Hence we have that sectoral labor shares can be decomposed into intermediate-adjusted expenditure share and net export share components in the following manner:

$$
\left[\begin{array}{c}
l_{1 a} \\
l_{1 m} \\
l_{1 s}
\end{array}\right]=\Omega^{-1}\left[\begin{array}{c}
X_{1 a} \\
X_{1 m} \\
X_{1 s}
\end{array}\right]+\Omega^{-1} \Lambda\left[\begin{array}{c}
N_{1 a} \\
N_{1 m}
\end{array}\right] .
$$

The formula above reduces to the corresponding formula for the world without intermediates when we set $\lambda_{i}=1, \forall i$. The corresponding formula for the closed economy is obtained by setting net exports to zero. 